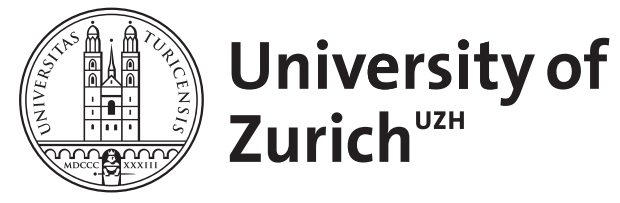

Zurich Open Repository and Archive

University of Zurich

University Library

Strickhofstrasse 39

CH-8057 Zurich

www.zora.uzh.ch

Year: 1984

\title{
Vergleich und Metapher im Hohenlied
}

Müller, Hans-Peter

Posted at the Zurich Open Repository and Archive, University of Zurich

ZORA URL: https://doi.org/10.5167/uzh-151798

Monograph

Published Version

Originally published at:

Müller, Hans-Peter (1984). Vergleich und Metapher im Hohenlied. Freiburg, Switzerland / Göttingen, Germany: Universitätsverlag / Vandenhoeck Ruprecht. 


$$
\text { MÚLLER }
$$

VERGLEICH UND METAPHER IM HOHENLIED 


\section{ORBIS BIBLICUS ET ORIENTALIS}

Im Auftrag des Biblischen Instituts der Universität

Freiburg Schweiz

des Seminars für biblische Zeitgeschichte

der Universität Münster i. W.

und der Schweizerischen Gesellschaft

für orientalische Altertumswissenschaft

herausgegeben von

Othmar Keel,

unter Mitarbeit von Erich Zenger und Albert de Pury

Zum Autor:

Hans-Peter Müller (1934) studierte evangelische Theologie und orientalische Sprachen, war von 1959 bis 1964 Pastor in Berlin, promovierte 1963 bei Claus Westermann zum Dr. theol., wurde 1967 in Münster (Westfalen) habilitiert, lehrte dort Altes Testament, ging 1978 nach Hamburg, um 1983 nach Münster zurückzukehren, jetzt auf eine Professur für «Altes Testament einschließlich nordwestsemitischer Literaturen». Veröffentlichungen u.a.: Ursprünge und Strukturen alttestamentlicher Eschatologie, 1969; Hiob und seine Freunde, 1970; Das Hiobproblem, 1978; Jenseits der Entmythologisierung, 1978; zahlreiche Aufsätze zu Problemen des Alten Testaments und dessen altorientalischer Umwelt, zur althebräischen Philologie und zu theologischen Problemen in einschlägigen Zeitschriften. 


\title{
ORBIS BIBLICUS ET ORIENTALIS 56
}

\author{
HANS-PETER MÜLLER
}

\section{VERGLEICH UND METAPHER IM HOHENLIED}

UNIVERSITÄTSVERLAG FREIBURG SCHWEIZ VANDENHOECK \& RUPRECHT GÖTTINGEN 1984 
CIP-Kurztitelaufnabme der Deutschen Bibliotbek

Müller, Hans-Peter:

Vergleich und Methapher im Hohenlied /

Hans-Peter Müller

Freiburg (Schweiz): Universitätsverlag;

Göttingen: Vandenhoeck und Ruprecht, 1984.

(Orbis biblicus et orientalis; 56 )

ISBN 3-7278-0307-x (Universitätsverlag)

ISBN 3-525-53677-1 (Vandenhoeck und Ruprecht)

(C) 1984 by Universitätsverlag Freiburg Schweiz

Paulusdruckerei Freiburg Schweiz

Digitalisat erstellt durch Florian Lippke, Departement

für Biblische Studien, Universität Freiburg Schweiz 
Meiner lieben Frau

zum 24.4.1984 



\section{Inhaltsverzeichnis}

Die Aufgabe

I. Syntaktische Beobachtungen

1. Die prädikative Verbindung von Vergleichsempfänger und Vergleichsspender

2. Die appositionelle Verbindung von Vergleichsempfänger und Vergleichsspender

3. Die Substitution des Vergleichsempfängers durch den Vergleichsspender: eigentliche Metaphern

II. Semantische Beobachtungen

1. Der Vergleichskern

2. Die Vergleichserweiterungen

III. Dissonanz von Realität und Metapher

1. Metonymie

2. Metaphorik im strengen Sinne

IV. Realisierung des Metaphorischen

V. Theologische Ergebnisse

1. Zusammenfassung

2. Folgerungen 



\section{Die Aufgabe}

"Wir müssen die scheinbar profanen Welten und Sprachen der Literatur, der Künste und des Films 'entmystifizieren', um ihre 'heiligen' Elemente $z u$ erschließen, obwohl es natürlich ein unbeachtetes, verkleidetes und degradiertes 'Heiliges' ist". - Mit diesen Sätzen stellt der Religionshistoriker M. ELIADE ${ }^{1}$ der "Entlarvung" des religiösen Erlebrisses, seiner Zurückführung auf die geringerwertigen Tendenzen und Triebe, wie sie auf je verschiedene Weise KARL MARX und SIGMUND FREUD versucht haben, eine gleichsam umgekehrte Aufgabe gegenüber. Er hat dabei natürlich an moderne Literaturen und Künste gedacht, deren "Mystifikation" in ihrer vorgeblichen Profanität liegt. Daß es ein ähnliches Absinken des Heiligen zu Gestalten des bloß Ästhetischen aber schon in der Antike, ja in der Bibel gitt, soll im Folgenden gezeigt werden.

Am Beispiel von Vergleich und Metapher wollen wir eine - freilich recht partielle - Stiluntersuchung zum Hohenlied in Angriff nehmen. Für die meisten modernen Leser sind die Vergleiche und Metaphern des Hohenliedes wie gleiche und ähnliche Figuren sonst in der biblischen und orientalischen Poesie bekanntlich eher ein Hindernis des Genusses; dieses Hindernis fortzunehmen, indem sie seine Gründe bewußt macht, ist das erste Anliegen der Arbeit. Ihr eigentliches Interesse aber ist ein umfassenderes: was hier als "Stil" umschrieben werden soll, ist als ästhetische Form nicht mehr und nicht weniger als die Larve eines Daseinsentwurfs; darum will die Untersuchung die Bilderwelt des Hohenliedes als Ausdruck seines Wirklichkeitsverständnisses deuten, genauer: als Beispiel einer unbewußt religiösen Daseinsaneignung. Der Stil liefert, so genommen, ein vergleichsweise objektives Vriterium für den "Geist" eines biblischen Buches, ja für seine verhüllten Wahrheitsaussagen. Aber nicht nur hier verbirgt sich das Religiöse im dichterischen Analogen: zumindest in einer Dimension, im deskriptiven Reden über das Heilige, ist dessen Sprache, weil es eine weitergehende Adäquanz von Wort und Sache dabei nicht gibt, schlechthin immer analogisch. Die von ELIADE bezeichnete Verkleidung und Degradierung des Heiligen ins DichterischÄsthetische ist also nicht bloß das Zeichen eines Wahrheitsverlustes unserer Zeit; sie läßt auch vom Wesen des Heiligen etwas erkennen,

1 Die Sehnsucht nach dem Lirsprung, 1973, 156. 
da es in menschlicher Sprache nie wirklich anders als in Knechtsgestalten zu uns kommt.

Wir gehen bei unserer Arbeit insofern linguistisch vor, als wir (I) auf möglichst präzise syntaktische Beobachtungen (II) solche zum semantischen Gehalt einzelner Vergleiche und Metaphern folgen lassen; daran schließen sich (III) Erc̈rterungen zur semantischer Dissonanz von Realität und Metapher sowie (IV) $\mathbf{z u} \in$ inigen bemerkenswerten Versucken, das Metaphorische gleichsam in eine Realität des Verhaltens zurückzuholen. Abschließend (V) werden diejenigen theologischen Ergebnisse zusammengefabt, die über einen Beitrag zum Verständnis des Hohenliedes hinausreichen: sie betreffen nicht nur das gegenseitige Verkä1tnis von Wort und Sache bei der Konstitution von Wahrheit, sondern auch die Rolle, die Bewußtsein und Unterbewubtsein für den Inhalt religiöser Metaphern spielen, sowie Erkenntnistheorie und Ästhetik der Metapher als Medium der Wahrheitskonstitution.

Die herangezogenen Texte aus dem Hohenlied dienen also lediglich als Paradigmen für den religiösen Wahrheitsgehalt, der in Figuren wie vergleich und Metapher enthalter sein kann. Die vorliegende Arbeit will insofern ein Beitrag zur Hermeneutik religiöser Sprache sein. 
Die beiden Grundelemente jeden Vergleichs sind ein Vergleichsempfänger und ein Vergleichsspender. Etwas wird mit etwas anderem verglicken, zum Beispiel die Angeredete mit der Blume in H. HEINES bekanntem Vers "Du bist wie eine Blume, so hold und schön und rein". Die Angeredete ("Du") ist dabei der Vergleichsempfänger, die "Blume" der Vergleichsspender. Die Prädikate "hold, schön, rein" aber bezeichnen das tertium comparationis, das "Dritte des Vergleichs", dasjenige also, worin Vergleichsempfänger und Vergleichsspender übereinkommen sollen.

Die syntaktische Verbindung nun zwischen der Bezeichnung des Vergleichsempfängers und der des Vergleichsspenders kann (1) prädikativ - wie im Fall des Heine-Verses - oder (2) appositionell sein; in beiden Fällen sprechen wir im engeren Sinne von einem Vergleick. Daneben aber kann (3) die Bezeichnung des Vergleichsspenders die des Vergleichsempfängers ersetzen (substituieren), hier im besonderen sprechen wir von der Metapher ${ }^{2}$.

1. Die prädikative Verbindung von Vergleichsempfänger und Vergleichsspender.

a) Durch die prädikative Verbindung von Vergleichsempfänger und Vergleichsspender entstehen in der hebräischen Dichtung zumeist Nominalsätze.

Für abendländisches Empfinden am auffälligsten ist dabei die asyndetische Zusammenfügung unter Verzicht auf eine Partikel wie $k^{e}$ oder $k^{e} \dot{m}$ "wie", etwa in:

${ }^{\prime a} n \hat{\imath} h^{a}$ bașșälät haššãón

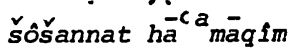

"Ich (bin) die Narzisse [?] ${ }^{3}$ von Saron,

die Lilie der Täler" (H1 2,1).

2 Auf eine Aufzählung jeweils aller Belege jeder syntaktischen Verbindung wird im folgenden verzichtet; es mag jedesmal ein Beispiel genügen.

3 thersetzung des unsicheren $h^{a}$ bassälät nach GERLEMAN, BK XVIII, 115 , WURTHWEIN, HAT I/18, 43, u. $\dot{a}$. 
Diese in gewisser Weise agramnatische Ronst.ruktion erlaubt noch keine Unterscheidurg von anders gemeinten syntaktischen Verbindungen, etwa von Prädikativen, die wir in deutscher tbersetzung Eit einer Präpositionalkonstrul:tion wiedergeben würden, zum Beispiel:

qôrôt bāttērû́ 'a räzím

"Die Balken unseres Hauses (sird) aus Zedern" $(1,17)$.

Ein Satz wie dieser ist, logisch beurteilt, ein Scheinvergleich, wie er in der Praxis freilich mit echten Vergleichen verwechselt werden oder auch in einen Vergleich übergehen kann ${ }^{4}$.

b) Die Partikeln $k^{e}$ und $k^{e}{ }_{m}{ }^{e}$ "wie" stehen dann als erstes Element im Dienst der genaueren syntaktischen (syndetischen) Verbindung der Satzglieder:

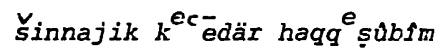

"Dein Haar ist wie eine Ziegenherde" $(4,2)$. Dem $k^{e}$ "wie" bei der Bezeichnung des Vergleichsspenders kann ein kēn "so" bei der des Vergleichsempfängers ertsprechen:

$k^{e}$ šb̆annā bên haḥ̂ḥ̂fm

kēn racjätí bên habbänôt

"Wie eine Lilie unter den Dornen,

so ist meine Freundin unter den Mädchen" $(2,2)$.

Schließlich sind etwa in 2,9 Vergleichsempfänger und Vergleichsspender durch das Partizip åomä $I^{e}$ "(ist) gleich dem" verbunden:

dômä dôdi liṣbi...

"Gleich (ist) mein Geliebter der Gazelle...".

Eine semantische Differenz ist durch das Nebeneinander von asyndetischen Verbindungen und solchen mit $k^{e} / k^{e}$ mo "wie" bzw. $k^{e} \ldots k \bar{e}^{-}$"wie...so" oder dômä $I^{e}$ "(ist) gleich dem" offenbar nicht angezeigt. Das ergibt sich schon daraus, daß in den Beschreibungsliedern Hl 5,(9) 10-16 und 7,1-6

4 Zu ähnlichen Erscheinungen im Sumerischer. HEIMPEL, Tierbilder $27 \mathrm{f}$. 54-65. 
beide Verbindungen promiscue gebraucht werden ${ }^{5}$. Ebenso ist kein Bedeutungsunterschied $\mathrm{zu}$ erkennen zwischen einer Wendung wie

cenajik jontm

"Deine Augen (sind) Tauben'( $1,15 \mathrm{~b} B ; 4,1 \mathrm{a})$

und

Cênāw ${ }^{e} j \delta$ inim

"Seine Aligen (sind) wie Tauben" $(5,12 a)$.

Auch bei den Verbirdungen mit $k^{e} / k^{e}$ mô "wie" u.ä. muß die genaue logische Beziehung zwischen dem Vergleichsempfänger und dem Vergleichsspender etenso erraten werden wie bei der. asyndetischen Sätzen: auch in den zuletzt genannten Beispielen werden nicht die Tauben als solche mit den Augen des Beschriebenen verglichen, sondern eben allein die Augen der Taube; durch die Ungebräuchlichkeit eines hier etwa zu verwendenden Determinativpronomens (deitsch: "wie diejeniger der Tauber") entsteht, obwohl nichts fortgefallen ist, was ebenso gut auch hätte dastehen kënnen, eine Art 1ogischer Ellifse ${ }^{6}$. Andere scheinbare Ungenauigkeiten sind durch die tngebräuchlichkeit einer Verbindung von $k$ "wie" mit anderen Partikeln bedingt; so bedeutet :

mî zôt 'ôlā min-hammicubār

${ }_{k}^{e}$ timm $^{a}$ rôt 'ä̀ān

"Wer ist's, die dort heraufsteigt aus der Wüste

wie ir Rauchsäulen" $(3,6,1)$.

Für "in" gibt es nach $k{ }^{e}$ "wie" im Hebräischen keine Ausdrucksmc̈glichkeit.

5 In der modernen Lyrik scheint das anders zu sein: wenn es $z$. B. in einem Gedicht von MAX HÖLZER heißt "Unser Bett ist ein fliegender Fisch", so würde ein zwischen Subjekt und Prädikativ tretendes "wi.e" den Schock, den das 0xymoron auslöst, zwar vermindern; die Wirkung der Zeile aber beschränkte sich auf das Erstaunen über ihre semantische Willkür. Eine grundsätzliche Differenz liegt freilich darin, daß im Deutschen die Verwendung des "wie" beim Vergleich unverzichtbarer zu sein scheint als im Hebräischen; im Falle des HöLZER-Verses nimmt das auffällige Fehlen des "wie" darum den Ausdruck geger den Verdacht der Banalität in Schutz.

6 Syntaktisch stringent ist dagegen ein Vergleich, bei dem die genauere Bezeichnung des Vergleichsempfängers in der Bildhälfte wiederholt wird, etwa 4,11b:

$w^{e}{ }^{-a} h$ śalmötajik

${ }_{k}^{e} r \bar{e}^{-a} I^{e}$ bänon

"Der Duft deiner Gewänder

(ist) wie der Duft des Libanon". 
Aber das Prädikat kann auch ein Adjektiv sein, das - wiederum wie in dem zitierten Vers H. HEINES - das tertium comparationis auf einen Begriff bringt; die Bezeichnung des Vergleichsspenders wird dann wit einem Korrelativ an die des Vergleichsempfängers angeschlossen:

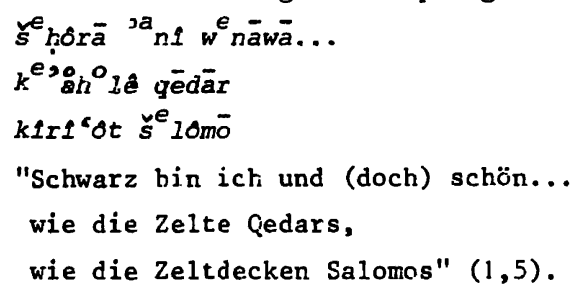

Erst hier wird die logische Beziehung zwischen Vergleicksempfänger und Vergleichsspender ausdrücklich als Analogie bestimmt: Die Verbindung von 'primum comparationis' und 'secundum comparationis' wird durch ausdrückliche Nennung eines 'tertium comparationis' stringent.

Eine Variante dieser grammatischen Verbindung ist der komparative Vergleich: das Adjektiv, welches hier die Ebenen bezeichnet, auf der die Analogie zwischen Vergleichsempfänger und Vergleichsspender gesucht werden soll, wird statt mit $k^{e} / k^{e}$ mó "wie" mit einem min "als" verbunden:

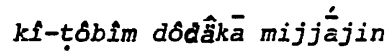

"Fürwahr, besser ist deine Liebe als Wein" $(1,2 b)$. Las Adjektiv dakei kann, wie im Falle des akkadischen stativs ${ }^{7}$, wie ein Verb konjugiert werden, ohne daß die Nominalstruktur, die für den Stil charakteristisch ist, verlassen würde:

mä-țôbû dôdajik mijjajin

"Wieviel besser ist deine Liebe als Wein" $(4,10)$. Trotz der scheinbaren 'Perfektform' tôbû "gut/besser ist" liegt kein eigentlicher Verbalsatz vor.

Nur in 4,10 wird das tertium comparationis durch $e$ in fientisches (Handlungen bezeichnendes) Vert angegeben. Scheint sick der Vergleich insofern

7 Zur Konjugation ces Nomers im. Akkadischen h. VON SODEN, Grundriß der akkadischen Grammatik, 1952, 100f. (\$77): "Jedes Nomen kann in den Stativ gesetzt verden; Bedeutung: ' $€$ r ist..., ich war...usw."." Formal entspricht der akkadische Stativ dem hebräischen 'Fer rekt'; es ist damit zu rechnen, daß das hebräische Perfekt bei zustandsverben, insbesondere bei sclchen nominaler At:leiturg, stativische Funktion hat. 
sachlich vom herkömmlichen Nominalstil zu entfernen, so macht sich die Konvention doch in der Form bemerkbar; das Verb begegnet als Partizip; mî-zôt hannišquāpā ke mô šăhar

"Wer ist's, die herabblickt wie Morgenrot?" $(6,10)$.

Verbale Vergleiche sind für das Epos, nicht für die Lyrik charakteristisch: wir kennen sie vor allem aus Homer ${ }^{8}$.

Ein eigentlicher Verbalsatz wie

nazkîrā dôdâkā mijjajin

"Wir wollen deine Liebe höher preisen als Wein" $(1,4)$

ist, streng genommen, metasprachlicher Art. Der komparative Vergleich geschieht als eine Selbstaufforderung: Gegenstand des Satzes ist nicht die Liebe, sondern das preisende Sprechen über sie; insofern handelt es sich nicht um ein unmittelbar gegenstandsbezogenes Sprechen, sondern bereits um ein Sprechen über die Sprache.

c) An Sätze mit prädikativen Vergleichen im Nominalstil können Sätze mit Verben im Jussiv anschließen, die offenbar gegenüber ersteren explikativen Charakter haben, d.h. die Verbindung von Vergleichsempfänger und Vergleichsspender wird noch einmal ausdrücklich hergestellt. Der Jussivsatz bringt dabei das tertium comparationis in die Wunschform. So folgt in 7,3a auf die asyndetische Prädikation

šar ${ }^{e}$ rék 'aggan hassahar

"Dein Nabel [?] (ist) eine runde [?] Schale"

der Wunschsatz

'al jähsar hammázäg

"nicht mangle der Mischwein";

die Verbindung beider Elemente ist noch enger, wenn der Wunschsatz die Phraseologie des Vergleichssatzes zum Teil wiederholt: in 7,8f. folgt auf

$8 \mathrm{Vg} 1$. etwa den doppelten verbalen Vergleich beim Bericht von der Blendung des Polyphem (Odyssee IX 384-394):

"...Wie wenn ein Mann, den Bohrer lenkend, ein Schiffsholz Bohrt; die Unteren ziehen an beiden Enden des Riemens, Wirbeln ihn hin und her, und er fliegt in dringender Eile; Also stießen auch wir in das Auge den glühenden Knüttel, Drehten, und heißes Blut umquoll die dringende Spitze.

...

Wie wenn ein kluger Schmied die Holzaxt oder das Schlichtbeil Aus der Ess' in den kühlenden Trog, der sprudelnd emporbraust, Wirft und härtet - denn das erneut die Kräfte des Eisens Also zischte das Aug' um die feurige Spitze des ölbrands." 
zot gomātēk dāme ${ }^{\epsilon} \bar{a}^{e} I^{e} t \bar{m} m a ̄ r$

w'šădajik $1^{e^{e}}$ askōlot

"Das ist dein Wuchs; er gleicht (dem) der Dattelpalme 9

und deine Brüste den (scil. deren) Trauben"

nach einer Selbstaufforderung der Wunschsatz

w⿳亠 jihjûnā šădajik

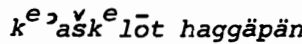

$w^{e}{ }^{e} \bar{e}^{-a} h_{l}$ 'appēk kattapunim

"so seien deine Brüste

wie Trauben (an) der Rebe,

und der Hauch deiner Nase wie (der Duft von) Äpfel(n)".

Solchen explikativen Wunschsätzen können Imperative an die Seite gestellt werden, die entweder wieder andere Imperative mit Hilfe eines Vergleichs entfalten, wie in 8,14 , wo auf die Aufforderung

$b^{e} r a h$ dodf

"Eile, mein Geliebter"

die vergleichende Entfaltung Eolgt

$\hat{u} c^{e} e_{\bar{e}} l^{e} k \bar{a}$ lișkî̀

गo I ec ôpär hä'ajjālím

"und sei gleich der Gazelle

oder dem Jurghirsch!"

oder die praktisch einen anderen Imperativ ersetzen wie $2,17 \mathrm{~b}$

sōb $d^{e} \overline{m e}-1{ }^{e} k \bar{~}$ dôdi liṣbi

o $I^{e c}$ opär hä̉ajjälsm

"auf mein Geliebter, sei gleich der Gazelle

oder dem Junghirsch!"

In 1,9 schließlich ist die Bezeichnung des Vergleichsspenders mit der des Vergleichsempfängers durch eine performative Ferfektform in der

1. Person des Sprechenden verbunden:

9 Genau genommen handelt es sich bei $d \bar{a} m^{e}$ tà $I^{e}$ tämār "gleicht (dem Wuchs) der Lattelpalme" um einen asyndetischen Relativsatz, dessen exaktere Wiedergabe als Relativsatz für deutsches Sprachgefühl freilich die lyrische Sprachform sprengen würde. Das Perfekt däme tä "gleicht" hat wieder stativische Funktion. 


\section{$I^{e}$ susāti b ${ }^{e}$ rikbê parc ô \\ dimmitık racjātik}

"Einer Stute an dem Streitwagen Pharaos

vergleiche ich dich, meine Freundin".

Doch können auch beide durch ein kognitives Perfekt stativischer Funktion in der auf den Vergleichsempfänger bezogenen 3. Person verknüpft sein, so in dem schon zitierten Satz:

\section{zót gômāték däm ${ }^{e} t \bar{a} I^{e}$ tämār}

"Das ist dein Wuchs; er gleicht (dem) der Dattelpalme" 7,8a. Von dem ebenso bezogenen Partizip $d \delta \overline{m a}_{1} e$ "(ist) gleich dem" 2,9a war oben die Rede.

d) Es ist wahrscheinlich, daß die hier dargebotene Rangfolge von einer asyntaktischen Verbindung des Vergleichsempfängers mit dem Vergleichsspender hin zur syntaktisch präzisen Verknüpfung beider durch eine finite Verbform der Genese des Vergleichs entspricht ${ }^{10}$. Unsere Darstellung folgt dann dem Weg zu einer immer exakteren logischen Verbindung der Vergleichsglieder, die sich in einer Intensivierung der grammatischen Kontinuität beider ausspricht ${ }^{11}$. Natürlich brauchen sich dabei etwa schon vorhandene Vorstellungen vom Verhältnis von Bild und Sache nicht geändert zu haben, worüber allerdings schwerlich etwas auszumachen sein wird. Eine schon immer gegebene implizite Verknüpfung würde dann bei größerer syntaktischer stringenz explizit geworden sein.

Immerhin ist nicht ohne Belang, daß die überwiegende Mehrzahl der im Hohenlied vorkommerden Vergleiche doch die Form von beschreibenden Nominalsätzen bewahrt hat, bei denen durch eine semantische Dissonanz,

10 Am Beispiel des Lyrischen gemessen, erscheinen die asyndetischen Sätze als angemessener. Mit Recht urteilt E. STAIGER: "Die Sprache scheint im Lyrischen auf vieles wieder zu verzichten, was sie in allmählicher Entwicklung von parataktischer zu hypotaktischer Fügung... in Richtung auf logische Deutlichkeit gewonnen hat" (Grundbegriffe 28).

11 Die phylogenetische Entwicklung der Sprache von der Agrammatikalität zur syntaktischen Kontiguität wiederholt sich ontogenetisch im Spracherwerb des Kindes. Bei. bestimmten Formen pathologischer Aphasie läuft der Prozeß rückwärts ab; vgl. R. JAKOBSON, Zwei Seiten der Sprache und zwei Typen aphatischer Störungen, in: Aufsätze zur Linguistik und Poetik, 1974, 117-141. 
die zwischen der Bezeichnung des Vergleichsempfängers und der des Vergleichsspenders gelegentlich besteht, ein Reiz des altertümlich-Erlesenen, ja des esoterisch-Seltsamen hervorgerufen wird. Je weniger der Vergleich zum Verglichenen zu passen scheint, umso eher ist deutlich, daß er gleichsam eine seit langem abwesende magische Wirklichkeit beschwört, für die er den Vergleichsempfänger lediglich als Analogieträger, ja oft als zufälligen Anlaß in Anspruch nimmt. Hier also implizieren die nominalen Kombinationen eine Art atavistischer Sprachmagie, insofern sie den beschriebenen Gegenstand mit Vorstellungen von Wesen und Dingen verschmelzen, die ihm nur noch in der Helt der Dichtung adäquat sind.

Doch zeigen auch die Jussive, insbesonders aber die Imperative als Ausdrucksformen des Wunsches, daß die Verbindung zwischen Vergleichsempfänger und Vergleichsspender ursprünglich magischer Art ist. So wie Jussive und Imperative beim Zauberspruch verwendet werden ${ }^{12}$, fügt der Vergleich dem Vergleichsempfänger etwas vom Wesen des Vergleichsspenders hinzu. Vollends das performative Perfekt dimmit 1 "vergleiche ich (hiermit)" 1,9 expliziert eine sprachmagische Handlung: performativ ist sie nämlich in dem Maße, wie sie die Gleichheit von Vergleichsspender und Vergleichsgegenstand durch den Sprechakt des Vergleichens allererst herstellt und dabei die Welt des sprechenden Menschen, die sprachlich erschlossene Welt verändert ${ }^{13}$.

e) Endlich kann die Verbindung von Vergleichsempfänger und Vergleichsspender durch einen indikativisch aussagenden Verbalsatz erfolgen, der dem Vergleich angefügt wird: die sprachmagische Verwandlung des verglichenen Gegenstandes, der nur in der Dichtung sinnvolle widerspruch gegen dessen bloße Realität, tritt zurück; die Sprachleistung des Vergleichs reduziert sich auf einen kognitiven Inhalt, fast auf eine Information. So folgt in 1,13 auf eine beziehungsreiche Kombination wie

$s^{e}$ rôr harmór dódf li

"Ein Myrrhenbeutel ist mir mein Geliebter"

12 Zum Imperativ im Zauberspruch vg1. Num 21,17 ; Jos 10,12;2Sam 16,7, zum Jussiv die Schöpferworte Gottes Gen 1,6.9.14.20.24. Imperativ und Jussiv sind miteinander in dem Zauberspruch verbunden, mit dem Jahwe nach Jes 45,8a $\alpha$ die neue Schöpfung hervorruft.

13 Inscfern ist es zu wenig, Vergleiche als Entdeckungen von Gemeinsamkeiten (VON RAD, Weisheit 160) zu verstehen. 
eine geradezu das Banale berührende Angabe des tertium comparationis wie bên šădaj jālin

"zwischen meinen Brüsten verbringt er die Nacht"14, womit Aussagesätze wie 2,3b.5b; 6,12a, Aufforderungen wie 5,1b;6,5a oder eine Ankündigung wie $7,13 \mathrm{~b}$ in ihrem Zusammenhang zu vergleichen sind ${ }^{15}$.

2. Die appositionelle Verbindung von Vergleichsempfänger und Vergleichsspender

Ein andermal tritt die Bezeichnung des Vergleichsspenders als Apposition neben die unmittelbare Bezeichnung des Vergleichsempfängers, etwa in einer Anrede wie 5,2

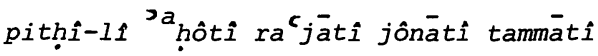

"Öffne mir, meine Schwester, meine Freundin, meine Taube, meine Makellose",

worin die unmittelbare Bezeichnung der Angeredeten racjāti "meine Freundin" durch die beiden Umschreibungsbegriffe "ọôtî "meine Schwester" und jônātî "meine Taube" als Appositionen ergänzt wird. Es ist dabei schwer zu entscheiden, ob die Verbindung der Appositionen mit ihrem Beziehungswort als syndetisch empfunden wurde. Eine logische Beziehung wird insofern hergestellt, als das tertium comparationis zu jônātî "meine Taube" danach in der dritten Apposition tammātí "meine Makellose" ausdrücklich genannt wird: was die Geliebte mit der Taube vergleichbar macht, ist ihre körperliche Fehllosigkeit. Die logische Klarheit nimmt dem Vergleich dabei freilich das sprachmagische Geheimnis; die Zeile wirkt denn auch verhältnismäßig prosaisch, wozu noch die phonetisch bedenkliche Häufung des gleichen Endmorphems -āti "meine..." beiträgt.

14 Zur Übersetzung WÜRTHWEIN, HAT I 18,42.

15 Gelegentlich freilich bleibt der auflösende Satz mit einem seiner Elemente im Metaphorischen verhaftet, wodurch dessen Geheimnis ein Stück weit erhalten bleibt: so steht in 7,14b șāpant $\hat{\imath}$ "habe ich verborgen" zwar außerhalb der Metapher - Äpfel werden gewöhnlich nicht versteckt -; weil sie aber unausgesprochen das Objekt zu SPN bilden bzw. ein anderes objekt nicht genannt wird, ist auch diese Applikation immer noch metaphorisch. Ähnlich wird durch die Aufforderung "mein Liebster komme" 4,16b und durch die Ankündigung "ich komme" 5, la mit der Zielangabe "in seinen/meinen Garten" der Bereich des Metaphorischen nur tendentiell verlassen. 
3. Die Substitution des Vergleichsempfängers durch den Vergleichsspender: eigentliche Metaphern

Schließlich kann der Vergleichsspender durch Substitution auch ganz an die Stelle einer unmittelbaren Bezeichnung des Vergleichsempfängers treten. Ein Satz wie 1,12

"Solange der König um mich ist, spendet meine Narde ihren Duft"

wird vom Hörer bzw. Leser bereits als befremdend empfunden worden sein: um die Geliebte ist normalerweise kein "könig", ebenso wie ihr, wo es nur natürlich zugeht, nicht pï̈tzlich auf wunderbarer Weise der Duft einer teuren Salbe entströmt. Zwar weiß jeder, daß die Figur des "Königs" den Geliebten verbirgt; aber es sollte vermutlich schon in der Antike poetisch zweideutig bleiben, was mit der Duft verströmenden "Narde" gemeint sei. Medizinische Belehrungen etwa wären darum auch in der Exegese nicht angebracht. Die Verschlüsselung gibt den Begriffen nun ganz bewußt etwas rätselhaft-Vieldeutiges, ja Dissonantes, wotei der Widerspruch gegenüber der Realität die Poesie des Textes ausmacht.

Nach der im Abendland konventionellen Terminologie kann man m.E. nur, wo Substitutionen dieser Art vorliegen, statt von einem Vergleich von einer Metapher reden ${ }^{16}$, obwohl schon der prädikative wie der appositionelle Gebrauch zum substitutiven überlejtet und sich die eigentlich funktionelle Differenz von Vergleick und Metapher so als fließend herausstel1t ${ }^{17}$. Denn da selbst die asyndetische Zuordnung von Vergleichsempfänger und Vergleichsspender in Sätzen wie "Ich (bin) die Narzisse von Saron" eine gedachte Verbindung zwischen beiden herstellt, auch

16 Vgl. etwa JÜLICHER, Gleichnisreden I,52: "In der $\mu \varepsilon \tau \alpha \varphi \circ \rho \alpha ́$ verschwindet im Ausdruck die Sache oder die Person, von der die Rede ist, hinter etwas ähnlichem, das direkt an ihrer Stelle auftritt." Dagegen sucht SELLIN (ZThK 75, bes. 300) nachzuweisen, daB die Metapher nicht das Ergebnis einer Substitution ist, sondern vielmehr der textsemantisch und situationsbezogen zu verstehenden Aufeinanderprojektion zweier Ebenen zuzuordnen ist. Vermutlich ist die Polemik SELLINS aber nur gegen einen zu engen Substitutionsbegriff wirksam.

17 Erst in der neueren Lyrik gibt es "Metaphorik, bei der es schwer hält, vorangehende Vergleichstätigkeiten anzunehmen"; angesichts dieses durchaus partiellen Befundes wird es m.E. nicht "fraglich gemacht, ob die Erklärung des abgekürzten Vergleichs wirklich das Wesen der Metapher trifft" (gegen KAYSER, Kunstwerk 124). 
wenn diese grammatisch nicht expliziert wird, kann von einem Verzicht auf die sprachliche Ausführung und die logische Stringenz des Vergleichs, wie sie für die Metapher vorausgesetzt wird ${ }^{18}$, erst bei einer substitutiven Benennung des Vergleichsspenders statt des Vergleichsempfängers die Rede sein. Erst hier handelt es sich im Sinne Quintilians wirklich um einen "kürzeren Vergleich" (metaphora brevior est similitudo ${ }^{19}$ ); erst hier schwindet das BewuBtsein einer Differenz zwischen Vergleichsempfänger und Vergleichsspender, die vielmehr durch die Substitution identisch zu werden scheinen ${ }^{20}$. Mit anderen Worten: Die Substitution des Verglichenen durch einen Bildbegriff kann ein Oxymoron hervorrufen, das den Widerspruch der Metapher gegen die Realität auf die kürzest mögliche Formel bringt" 21 daß der Geliebte kein "König" ist und es doch sein soll, wird als Dissonanz besonders deutlich empfunden, wenn das Wort "König" für die Bezeichnung des Geliebten eintritt.

$18 \mathrm{Vg} 1$. etwa G.VON WILPERT (Sachwörterbuch der Literatur, 51969, 480), wonach die Metapher "ohne formale Ausführung des Vergleichs im Nebeneinander der Verte ('so - vie') unmittelbar und komplex anstelle desselben tritt".

19 Institutio oratoria VIII 6,8 .

20 Zugleich mag die metaphorische Substitution archaischen Bedürfnissen eines Sprachtabus entsprechen, wenngleich es übereilt erscheint, im Sprachtabu generell die Wurzel von (Vergleich und) Metapher zu sehen.

21 H. h'EINRICH (Sprache 295-316) sieht gerade in der geringen Abweichung einer Metapher von der unmittelbaren Bezeichnung der sinnlich erfahrbaren Realität deren Kühnheit begründet: die kühne Metapher ist gerade bei einer kleinen Spannung zwischen dem Gegenstand und dem Bild für ihn "eine Prädilation, deren Widersprüchlichkeit nicht unbemerkt bleiben kann" (308); gerade die kleinere Differenz ist um so auffälliger, als sie dem sicher Erwarteten strikter zuwiderläuft. Der Gegensatz zum Metapher-Begriff in der Formulierung Quintilians ist nicht erheblich: denn gerade die indiskursive "Kürze", die die Metapher im Gegensatz zum Vergleich auszeichnet, beruht auf dem Mangel an einem begrifflich explizierten tertium comparationis, d.h. auf dem Defizit an einer plausiblen Verbindung von Vergleichsempfänger und Vergleichsspender; dieser Mangel ermöglicht den Widerspruch gegen die Realität, dieses (kaum merkliche) Defizit macht die Metapher kühn. Wir gestehen freilich $z u$, daß die Bezeichnung der Kürze eines Vergleichs als indiskursiv selbst etwas Metaphorisches hat: zunächst ist Kürze ja mit dem Längenmaß, nicht mit der Logik zu bemessen. - Daß das Urteil "brevior" ein "posterior" im genetischen Sinne impliziere, ist, sofern es der Fall sein sollte, von geringerem Belang: in der Tat scheint die logische Explikation der metaphorischen Substitution spät zu erfolgen; wo sie geschieht, wird die struktur der Metapher erklärt - und zugleich aufgelöst. 
Vergleiche und Metaphern werden im Hohenlied fast ausschließlich auf den lyrisch verklärten Menschen und die Attribute des Liebenden angewendet. Was die semantische Leistung der Einzelvergleiche und metaphern anbetrifft, so ist zwischen (1) der eines bildhaften Vergleictskerns ${ }^{22}$ und (2) verschiedenen Gestalten der Vergleichserweiterung zu unterscheiden.

\section{Der Vergleichskern}

Der semantische Gehalt des Vergleichskerns läßt sich am ehesten aus einer Unterscheidung der Bereiche entnehmen, denen das Bildmaterial des Vergleichs bzw. der Metapher entstammt. Ein erster Uber:lick läßt sich insofern leicht gewinnen, als sich a) Sachvergleiche von b) Pflanzen- und c) Tiervergleichen trennen lassen; schwieriger ist es, zu prüfen, welche Kriterien oder Regeln die jeweilige Wahl des Vergleichsspenders steuern. Hahen wir es bei der Unterscheidung von Sach-, Pflanzen- und Tiervergleichen gleichsam mit einer Semantik des Vordergrunds zu tun, so zeigt sich als unhewußter religiöser Hintergrund d) die magische Gleichsetzung der Frau mit Acker und Erde, e) die gesellige Travestie, die den alltäglichen gesellschaftlichen Platz mit dem einer dichterischen Wunschwelt vertauscht, und $f$ ) so etwas wie eine theomorphe Steigerung des lyrisch verklärten Menschen mittels des Bildes, so daß die Exegese des Hohenliedes in sehr partieller Aufnahme einstiger "mythischer" Deutungsversuche ${ }^{23}$ an den Schilderungen des Menschen Ausdrucksreste älterer numinoser Erfahrungen wiederzuerkennen vermag.

a) Am häufigsten sind innerhalb der Vergleichskerne die Sachvergleiche: Bilder für den besungenen Menschen werden der Dingwelt entnommen.

22 Nicht bildhaft ist trotz des Gebrauchs von $k^{e}$ "wie" offenbar der

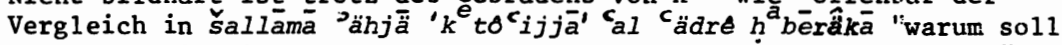
ich sein 'wie eine Umherirrende' bei den Herden deiner Genossen?" $(1,7)$ oder in 'áz hajjit b b ênaw k mós at šalôm "so bin ich in seinen Augen wie eine, die das Glück gefunden hat" $(8,10)$. - Die nichtbildhaften Vergleiche bleiben hier unerörtert.

23 Als eine Sammlung von Passahgesängen kanaanäischen Ursprungs, in denen pagane Gottheiter die ihrem Mythos entsprechenden Rollen spielen, hat zuerst W. ERBT (Die Hebräer, 1906, 197ff.; Handbuch zum Alten Testament, 1909, 30ff.) das Hohelied gedeutet; vom Liebesverhältnis zwischen Gott und Göttin her wird es danach von W. WITTEKINDT, M. HALLER, G. WIDENCREN, H. RINGGREN, H. SCHMÖKEL u.a. interpretiert. 
Insbesondere dominiert eine Terminologie aus dem Bereich der bildenden Kunst bzw. eines Kunsthandwerks, mit dessen Produkten die gutsituierten Kreise, in denen das hohelied seinen sozialen Ort hatt $e^{24}$, umzugehen pflegen. So scheint in Beschreibungsliedern wic Hl 5,(9)10-16 oder 7,1-6 nicht der bzw. die Geliebte, sondern eine Skulptur geschildert zu sein ${ }^{25}$, so schon 5,10-16 in dem elliptischen Satz V.1la

róšô kätäm (u)pāz 26

Sein Haupt (ist wie aus) strahlendem Golde ${ }^{27}$.

Des weiteren werden im gleichen Gedicht die Hände des Geliebten als goldene Walzen (14a), sein Bauch als eine Elfenbeinplatte (17b), seine Beine als Alabastersäulen (15a) angesprochen. Entsprechend erscheinen in der Beschreibung der Šulammit 7,1-6 die Rundungen ihrer Hüften als "Halsgeschmeide, Gebilde von Künstlerhänden" (2a), ihr Nabel als runde Schale für Mischwein (3a), der Hals als ein Elfenbeinturm (5a) ${ }^{28}$ und das gelöste Haupthaar als Purpur $(6 a \beta)$. Daneben kommt im Hohenlied als Vergleichsspender für die Lippen der Karmesinfaden vor $(4,3 a)$; der Wert, den die Geliebte für den Liebenden darstellt, wird 8,6 dem auf der

24 Zum sozialen Ort des Hohenliedes vgl, einstweilen Vf.: ZAW 90, $259 f$.

25 Das entspricht der: Ursprung des Beschreibungsliedes als Gattung: deren Vorbild scheint die kultische Beschreibungshymne zu sein, die die Schönheit einer Göttin nach dem Modell ihres Kultbildes preist (HERRMANN: ZAW 75, 177-179). Speziell die Beziehung der Menschendarstellungen des Hohenliedes zur Kleinplastik hat GERLEN:AN (BK XVIII, 65 u.ö.) betont, wobei man den Vergleich aber m.E. nicht auf die ägyptische Kleinplastik beschränken darf.

26 Die Lesung Tפ̣ 7 legt sich von LXX her nahe, ater auch von Dan 10,5,

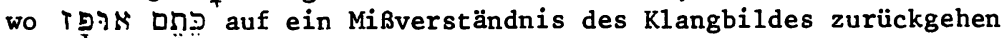
dürfte.

27 Die Wortkombination kätäm ( $\hat{u}) p \bar{z} z$ findet sich noch Dan 10,5 und Tanh Waëra 8 (M. JASTROW, A Dictionary of the Targumim, the Talmud Babii and Yerushalmi, and the Midrashic Literature 2, Nachdruck 1967, 1149), vgl. im AT zahäb mopáz l Kön 10,18 und paz // kätäm 'opîr Jes 13,12; zu pāz vgl. Amarna 22 II:56 p[a-a?-]az/s-na-an-ni "Gold", dazu W.VON SODEN, Akkadisches Handwörterbuch 2, 1972, 852b. Eine Bedeutungsdifferenz läbt sich zwischen beiden Begriffen nicht ausmachen; der Aufwand zweier gleichbedeutender Wörter mehrt deren suggestive Kraft. Eire wörtliche tbersetzung ins Deutsche ist nicht möglich.

28 Beim "Elfenbeinturm" muß es sich wohl um ein Gebilde der Kleinkunst handeln; die Verwendung des Artikels vor dem Genitiv gibt keinen Anlaß, an einen bestimmten Gegenstand, etwa ein bekanntes Bauwerk zu denken, vg1. Anm. 69. 
Brust getragene Siegel und dem Armreif gleichgesetzt ${ }^{29}$. - Daneben werden Sachvergleiche der Architektursprache entnommen: Bilder wie Turm $(8,10)$, Davidsturm $(4,4)$, Libanonturm $(7,5)$ Mauer und Tür $(8,9 f$.$) oder so be-$ fremdende Zusammenstellungen wie die Schönheit bzw. Lieblichkeit der Freundin mit der von Städten wie Thirza bzw. Jerusalem $(6,4)$. Auch Landschaften wie der Libanon $(4,11 ; 5,15)$ und der Karmel $(7,6)$ geben Vergleichsmaterial her, ja sogar deren Requisiten wie "die Teiche von Hesbon" $(7,5)$ oder "die Zelte Qedars" bzw. "die Zeldecken Salomos" (1,5). Schließlich gehören zur Bildwelt der Liebe Spezereien wie Narde $(1,12)$ und Salbe $(1,3 ; 4,10)$.

Die dichterische Wirkung solcher Sachvergleiche, die zwar einer Welt künstlerischer Verwirklichungen, zugleich aber auch der materiellen Sphäre entstammen, beruht einerseits auf einer Steigerung der im Bereich des Naturhaften vorgefundenen Humanität in den Bereich des Artifiziellen: indem sich die dichterische Imagination die Distanz des menschlichen Wesens von dessen realen Einzelerscheinungen bewußt hält, sublimiert sie die natürliche Gestalt des Menschen nach künstlerischen Mustern, die gleichsam eine 'innere Welt' ersetzen. Dabei wird im literarischen Medium realisiert, was auch die bildende Kunst des Alten Orients leistet: nicht auf eine Nachahmung der Natur zu zielen, sondern darzustellen, was man über das Wesen seines Gegenstandes zu wissen meint; trotz allem scheinbaren Realismus handelt es sich in altorientalischen Darstellungen ja um Denkbilder, nicht um Wiedergaben des sinnlich-Anschaulichen ${ }^{30}$.

29 Wie die Beschreibung lebender Menschen Modellen aus der Juwelierund Kunsthandwerkstatt folgt, zeigt auch die Beschreibung der Prinzessin $P b I$ im Werbelied des ugaritischen Krt vor deren Vater (CTA 14:143-148 [=KTU 1.14$]$ III : 39-44):

"Gib mir die Dame Hrj', die wohlgeborene, deine Erstgeburt, ... deren Augäpfel wie Gemmen von Lazurstein, deren Augen (?) wie Schälchen von Alabaster (?) sind."

30 So 0. KEEL, Jahwe-Visionen und Siegelkunst, 1977, 69, mit Hinweis auf w. WOLF, Die Kunst Ägyptens. Gestalt und Geschichte, 1957, passim. 
So zeigt auch die Dichtung einen überpersönlichen Prototyp, der gegenüber dem individuell-Bewegten der je einmaligen Men:jchengestalt so etwas wie Neutralität bewahrt ${ }^{31}$.

Andererseits bewirken die Sachvergleiche aber auch eine Frojektion des Humanums in einen nicht-menschlichen, ja stofflichen Zusammenhang. Dabei vollends zieht sich nicht nur die subjektive Bewegtheit des Individuums, sondern das Ich-Sein des Menschen überhaupt zurück. Fern einer nur allzuleicht ins Willkürliche abgleitenden Ichwelt wird der Menscli wieder ein Stück Natur. Da das Ich gegenüber dem Nicht-Nenschlichen wohl nirgends im Alten Orient schon in die einsame Fremdheit existentialer Einzigkeit getreten ist, steht die Natur auch nicht einfach im Iienst $\in$ iner menschlichen Selbstdarstellung; vielmekr bewirken die Sachvergleiche ein sprachliches Verschmelzen des Menschen mit den ikm vertrauten Dingen.

b) Inter den statistisch schwächer vertretenen Pflanzenvergleicher: spielen zunächst fruchttragende Bäume wie der Apfelbaum für den Jüngling $(2,3)^{32}$, die Dattelpalme für den Wuchs (qómā) des Mädchens $(7,8 f .)^{33}$

31 In diese Richtung weist noch einmal der Nominalstil: Nominalsätze sind die Sprachgebärde, die den Gegenstand, indem sie ihn zeigt, als etwas Ruhendes fixiert. Ist das Dargestellte ein tewegter fegenstand wie im Falle von H1 7,1-6, so entsteht eine Disgruenz von Sprachform und Inhalt: der "Sprachleit" des Gedichtes bannt den Leib der besungenen Geliebten ins Statuarische, ja Anorganische. "Daß Schönheit in der Bewegung erfahren wird" (WESTERMANN, FS ZIMME'RLI, 483), gilt insofern nur von der außersprachlichen Referenz des Gedichts; es wird nicht in der sprachlichen Verwirklichung der Erfahrung wiederhol.t. So scheint die lyrische Erfahrung menschlicher Schönheit im Hohenlied den Charakter des Schönen als eines Geschehenden zumindest in den Beschreibungsliedern zurückzustellen.

32 Der Vergleich des Mädchens mit einem "blühenden Garten von Apfelbäumen", wobei wie in Hl 2,3 das Motiv des Schattens assozilert wird, findet sich in dem Beschreibungslied, das einen sumerischen Liebeszauber einleitet:

"Wenn das junge Mädchen sitzt, ist es ein blühender Garten von Apfelbäumen,...

ist. es ein Zedernast, der Schatten spendet."

FALKENSTEIN: ZA 56,115f. (2.6.8), der dazu S.121 auf die Parallele bei E. CHIERA, Sumerian Religious Texts, 1924, 31:28f., hinweist:

"Apfelbaum-Garten, der du mir Blüten trägst, deine Reize sind süß.

Apfelbaum-Garten, der du mir (reiche) Früchte trägst, deine Reize sind süß."

33 Vg1. die Dattelrispen von 5,11b. 
sowie der Cranatapfel für den Detailvergleich eine Rolle $(4,3.13 ; 6,7)$; die Gestalt ( $\operatorname{mar}^{2} \overline{\ddot{a}}$ ) des besungenen Mannes entspricht nach 5,15 der eines so erlesenen Baums wie der Zeder. - Unseren Konventionen näher liegen freilich Vergleiche mit Blumen $(2,1 \mathrm{f} ;$; $, 13, \mathrm{vgl} .7,3 \mathrm{bB})$ oder mit anderen Pflanzen, insbesondere solchen, die wie der Hennastrauch $(1,14)$ Farben oder wie Myrrhen $(1,13)$ und Balsam $(5,13)$ Spezereien liefern.

Die magische Idee einer letzten Identität von menschlicher und tellurischer Fruchtbarkeit mag das Bild des von Lilien umgebenen Weizenhaufens für den Leib der Frau $(7,3)$ berühren, ebenso die Zusammenstellurg der Liebe $(1,2.4 ; 2,4 ; 4,10)$ oder des beim Kuß berührten Gaumens $(4,10$, vg1. 5, 16) mit dem Wein und die der weiblichen Brüste mit dessen Trauben (7.9).

Schafft auch hier der Vergleich eine Teilhabe am Wesen des Verglichenen, so versetzt er den Menschen in den Raum jener Vitalkräfte, die die Pflanze der Erde entnimmt - zumindest für den Augenblick seiner lyrischen Verwandlung. Da Äpfel und Granatäpfel auch in der Liebesmagie verwendet werden 34 , mag die "Sprachmagie" sich ihrer ebenfalls bedienen. Speziell. Bäume wie die Palme ${ }^{35}$, vielleicht Früchte wie der Granatapfel ${ }^{36}$ werden darüber hinaus wegen ihrer Affinität zu bestimmten im Bewrßtsein längst versunkenen Göttern und Göttinner gewählt. Schon der Vergleich mit einer

34 Vgl. etwa R.D. BIGGS, Texts from Cuneiform Sources II, 1967, $70: 8,74: 4$.

35 Ri 20,33 nennt einen Ortsnamen bacal tämär, dem in 3015 IX $14 \mathrm{f}$. hjt tmr zu entsprechen scheint. K. GALLING (Biblisches Reallexikon, 1977, 34) erwägt, den ugaritischen Gott von ANEP 491, dessen Kopfputz er als Palmwedel deutet, mit diesem Baal zu identifizieren. Vielleicht bezieht sich_auf den "Palmenbaal" das theophore Element in den Klagenamen "itámār "Wo ist die Palme:" Ex 6,23 u.ö.; der Name Baals wäre dann substituiert wie in Jîzäbäl "Wo ist der Fürst (Baal)?"

36 Eine kassitisch beeinflubte Elfenbeineinlage aus Assur (13.Jh.) stellt Lebenswasser spendende Gottheiten als von stilisierten Granatapfeltäumen flankiert dar; später scheint der Granatapfel mit Adonis verbunden (J. EÖRKER-KLÄHN, RLA 3, 1957-71, 619b.626b). Die häufige Verwerdung des Granatapfels als Zierat an Sakralgewändern Ex 28,33f.; 39,24-26, in der Kultarchitektur lKön 8,18.20.42 u.ä., die am ornamentalen Gebrauch des Motivs u.a. an ejnem bronzenen dreifüBigen Ständer aus Lgarit ihre Entsprechung hat (vg1. P. WELTEN, Biblisches Reallexikon ${ }^{2}$ 193, Abb.45,10), läpt an die ähnliche Symbolfunktion der Palme lkön 6,29; Ez 41, $18 f f$. denken; Cranatapfel und Palme scheinen $\Lambda t t r i b u t e$ älterer Götter zu sein. 
Pflanze kann also den Vergleichsempfänger in den Bereich numinoser Wesen versetzen, wenn die Pflanze nämlich zu deren httributen gehört, Göttinnen etwa mit den betreffenden Blumen in den Händen dargestellt werden ${ }^{37}$.

c) Stärker als Sach- und Pflanzenvergleiche scheinen die Tiervergleiche im einzelnen auf ein konventionelles tertium comparationis und so auf einen bestimmten Symbolwert festgelegt zu sein. Gazelle $\left(s^{e} t i\right)$ und Junghirsch ('opär hä Jajjāllfm), in 2,9.17; 8,14 auf den Mann angewendet und dabei jedesmal zusammen genannt, sind wegen der behenden Schnelligkeit ihrer Bewegungen gewählt, wie der den Vergleich beherrschende Imperativ $b^{\epsilon^{\prime}}$ rạ "eile" $(8,14)$ zeigt $^{38}$. In 4,5 und 7,4 werden Kitze mit den weiblichen Brüsten in Verbindung gebracht. Mit dem appositionell gebrauchten Bild "meine Taube" ist 5,2 und 6,9 das Attribut tammātí "meine Makellose" verbunden, worin das tertium comparationis als solches ausdrücklich wird (vg1. I.2) ${ }^{39}$ : die Taube ist ein Beispiel körperlicher Fehllosigkeit, wie sie mit der Wendung mûm 'ên "kein Makel" und ohne Vergleich in 4,7b von dem Geliebten ausgesagt ist. Dazu würde etwa auch die Bezeichnung der Augen als Taubenaugen $(1,15 ; 4,1 ; 5,12)$ passen. Dagegen weckt die glei.che Metapher in 2,14 die Assoziation der Furchtsamkeit des sich gern verbergenden Vogels. - Beim Vergleich mit der Stute 1,9 ist deren reicher künstlicher Schmuck von Belang (V.lof.). Wenn vollends das Haar der Geliebten mit einer Ziegenterde, ihre Zähne mit einer Schafherde zusammengestellt werden $(4,1 \mathrm{f}, ; 6,5 \mathrm{f}$.$) , so zeigen Kontext und sumerische Paralle-$ $1 e n^{40}$, daß dabei an die große Zahl der Einzelexemplare als Vergleichspunkt gedacht ist.

37 Kanaanäische Göttinnen werden bekanntlich gern mit Kelchtlüten in den Händen dargestellt; vg1. etwa BARRELET: Syr 35, Tf.la (?), lb und 2d (letztere Figur verbindet Blume und Schlange), ANEP Abb. 470-475, GALIING, Biblisches Reallexikon 112f. (Abb. 31,2), 116f. (Abb. 31,12 [?]).

38 Daneben ist zu erwägen, ob nicht $s^{e} b_{\hat{I}}$ "Gazelle" auch wegen seines Gleichklangs mit $s$ bi "Zierde" gewählt wurde; die Wurzel des Vergleichs läge dann zugleich in einer Art $\mathrm{klangspiel,} \mathrm{so} \mathrm{daß} \mathrm{mit} \mathrm{einer} \mathrm{mehr-}$ fachen Determination des Bildes zu rechner wäre.

39 Anders scheint GERLEMAN (EK XVIII, 163) die Funktion von tamim zu verstehen.

40 Zum Topos 'Schaf' HEIMPEL, Tierbilder Nr. 14.1-14.5, zur Kombination von 'Schaf' und 'Ziege' Nr. 14.6-14.9. 
Insbesondere die Taube ${ }^{41}$, vielleicht auch der Hirsch ${ }^{42}$ mögen darüber hinaus wegen ihrer Affinität zu vorderasiatischen, vor allem syrischen Liebesgöttinnen gewählt sein, in deren Nähe sich ja auch Ziegen ${ }^{43}$ und wohl Steinböcke 44 finden, während die Gazellen Embleme für die Darstellung des Gottes Rašap ${ }^{45}$ 1iefert. So vermitteln auch die Tiervergleiche eine sprachmagische Teilhabe an der Aura atavistischer Götter: deren längst profanierte Symbole bilden jetzt Metaphern für die Aufwertung des poetisch verzauberten Menschen.

d) Eine archaisierende Gleichsetzung der Frau mit Acker ${ }^{46}$ und Erde klingt. in einem Vergleich nach wie

"Ein verschlossener Garten (ist) meine Schwester und Braut" $(4,12)^{47}$.

41 Dazu FAUTH, Aphrodite parakyptusa, 27-29,40f.58.82ff.101.108, und zuletzt U. WINTER bei: 0. KEEL, Vögel als Boten, 1977, 37-78 (dort die ältere Lit.) bes. 53.78. Ursprünglich mag das Bild der Göttin selbst Gestaltelemente ihres späteren Begleittieres gehabt haben; Material dazu bei BARRELET: Syr 32; ugaritische Textbelege zu Anat als geflügeltem Wesen bei WINTER (KEEL 62).

42 Hirsche haben im Kult der mesopotamischen Göttinnen Ninhursanga und Ninmah eine Rolle gespielt; der Gott Ningirsu kann u.a. als "Hirschkalb" "bezeichnet werden (HEIMPEL, RLA 4, 1972-5, 420).

$43 \mathrm{Vgl}$. das bekannte Bild der Astarte (?) auf der Elfenbeinplatte eines Grabes in Minet el-Beidá, wo diese die zu beiden Seiten anspringenden Ziegen füttert; C. SCHAEFFER, Ugaritica 1, 1939 (Titelbild). Auch die Genitivverbindung cašt ${ }^{e}$ rôt șôn Dtn 7,$13 ; 28,4.18$ dürfte in diesem Zusammenhang von Belang sein. Ferner H. SCHMÖKEL, Ziege am Lebensbaum, Af0 18 (1957/8) 373-378.

44 Dazu die ebenfalls bekannte Qadšu(?)-Plakette aus Ugarit, wo die nackte, auf einem Löwen stehende Göttin mit der Hathorfrisur Steinböcke oder Ziegen (Antilopen) in beiden Händen hält; C. SCHAEFFER, Ugaritica 2, 1949, 36 Abb. 10.

45 Vg1. D. CONRAD, Der Gott Reschef: 2 ZAW 83 (1971) 157-183, bes. 170f., P. WELTEN, Biblisches Reallexikon 107/8. - Zu einigen Siegeln, die auf eine Beziehung Marduks zur Gazelle schließen lassen, E. UNGER, RLA 3, $1957-71,153 / 4$.

46 Elementarer ist diese Identifikation noch in ugaritischen Texten. Nach CTA $23(=$ KTU 1.23):13.28 werden die Göttinnen atrt und $r h m(j)$ offenbar durch den sexuellen Akt zum "Feld der Götter" (sd ilm); vg1. die Gottesbezeichnung ttrt s $d$ "Astarte des Feldes" KTU 4.182:55, dazu J. NOUGAYROL, Ugaritica $5,1968,56$.

47 Zur Bezeichnung der Geliebten als Garten vgl. die Anm. 32 zitierten sumerischen Beispiele, dazu die Verwendung von $k i r{ }_{6}$ "Garten" Gudea Zyl B V 15 (FALKENSTEIN: ZA 56, 121/2). 
Die Metapher käräm "Weinberg" 48 wird 1,$6 ; 2,5 ; 8,11 \mathrm{f}$. substitutiv für den Leib der Frau gebraucht; von den sachlick benachbarten Zusamenstellungen der Liebe mit Wein u.ä. war oben (b) die Rede.

In lyrischer Verwandlung erfährt der Mensch so noch einmal eine Integration in die Natur seiner Umwelt; er flieht die Landschaftsferne des städischen Lebens ${ }^{49}$, auch wenn er dabei tereits konventionelle Erletrisreste etwa aus dem therdruß an hellenistischer Urbanität ${ }^{50}$ üternimnt. Freilich wird eine Integration. von Gesellschaft und Natur nicht mehr mit dem kollektiven Ernst gesucht, den primitive Gemeinschaften dabei einst an ihre geistige und physische Selbsterhaltung wendeten; die Identifikation der Besungenen mit Acker und Erde ist dichterisches Spiel von Individuen, die sich aus einer mehr oder weniger unbewußten Sehnsucht nach dem Ursprünglichen von gegenläufigen Konventionen ihrer Gesellschaft dispensieren. Was einmal Schrecken und Geborgenheit innerhalb eine unerschütterlichen kosmischsozialen Gefüges ausmachte, wird nun in wenigen ästhetischen Augenblicken von einzelnen wiedererweckt, $j a$ selbstmëchtig angeeignet; auBerhalb einer lyrischen Sehweise hat es veder Autorität noch Kraft, ja wird es widersinnig.

e) Vor den Sach-, Pflanzen- und Tiervergleichen sowie der Identifikation mit der Erde heben sich die Travestien $a b$, die nicht mit einer Integration des Menschen in die außermenschliche Uwwelt und deren numinose Instanzen spielen, sondern dem lyrisch Erregten helfen sollen, die Fesseln gesellschaftli.cher Positionen und Konventionen für den Augenblick der lyrischen Verzauberung hinter sich zu lassen.

48 Nach der ugaritischen Erzählung von der Liebe der Götter Jarib und Nikkal CTA 24 ( = KTU 1.24): 22f. will Jarib im sexuellen Akt "ihr (scil. Nikkals) Feld zu einem Weingarten, das Feld ihrer Liebe zu einem Obstgarten" machen; zur tbersetzung HERRMANN, Yarib ur.d Nikkal $14 \mathrm{f}$., anders H. CAQUOT-M.SZNYCER $\cdots$ A. HERDNER, Textes Ougaritiques. Tome 1: Mythes et legendes, 1974, 393.

49 Für die Beheimatung der Gedichte im städtischen Miliec sind_besonders die Begriffe $\varsigma_{\hat{i} r}$ "Stadt" $(3,2 f . ; 5,7)$, śûg "Straße" und $r$ hōb "Platz" $(3,2)$ und vor allem die Jerusalemerinnen als Statisten $(1, \dot{5} ; 2,7 ; 3,5$. $10 ; 5,8.16: 8,4)$ bezeichnend. Vg1. J. WINANDY, Le Cantique $45 \mathrm{f}$.

50 An eine Entstehung der Sammlung im dritten vorchristlichen Jahrhundert denken 0 . EISSFELDT, 0 . KAISER, M. HENGEL (Judentum und Hellenismus 1973, 210) u.a.; dabei kann vorausgesetzt werden, dab einzelne Stücke älter sind, genauer: bis in die frühe Königszeit zurückreichen. 
Am festesten dürfte die Geschwisternetapher in der Topik der Liebesdichtung verwurzelt gewesen sein: sie ist längst zu einem fixierten Element der Sondersprache Liebender geworden; weder im Mythos, noch im alltäglichen Leben ist für die Metapher eine Berechtigung in tatsächlichen Verhältnissen zu suchen. Dabei ist die Bezeichnung "ạotî kallē "meine Schwester (und) Braut" beinahe formelhaft $(4,9.12 ; 5,1)$; daneben findet sich "ậti ra ${ }^{C} j a ̄ t \hat{~}$ "meine Schwester (und) meine Freundin" (5,2; vgl. zu "āhôt "Schwester" allein 8,8). - Laß noch immer, wie wohl schon beim Ursprung der Metapher, die Verhüllung einer nur den Liebenden selbst offenbaren Beziehung das Motiv der Bruder-Schwester-Anrede ist ${ }^{51}$, zeigt die einzige Stelle, an der die Bruder-Anrede begegnet: das Geschwisterverhältnis nämlich gestattet dem Paar nach 8,1-4 ein von den strengen Regeln gesellschaftlicher Moral ungehindertes Zusammensein ${ }^{52}$.

Geht es inscweit bei der Geschwistermetapher um die dichterische Selbstbefreiung von einem Normensystem, so haben es die Königs- $(1,4.12 ; 3,[$ ia] $9-11 ; 7,1 \mathrm{f.6}[\mathrm{vg} 1.6,8 ; 8,11 \mathrm{f}].)^{53}$ und die Hirtentravestie $(1,7 \mathrm{f}$.$) , da$ beide einen gesellschaftlichen Positionswechsel - nach oben nämlich bzw. nach unten - vorsehen, mit einer eher "klassenspezifischen" Verwandlung zu tun. Dahei wird die urbane Königstravestie, wie die königsrolle, die auch der mit der Sammlung des Hohenliedes gleichzeitige Qôhälät nach Pred 1,12-2,12 experimentell übernimmt, der Sehnsucht eines wohlhabenden "Bürgertums" entsprechen, dem im ptolemäischen Diadochenstaat die wirkliche Macht entzogen war ${ }^{54}$. In denselben städtischen Kreisen kann aber zugleich die Zivilisationsflucht teheimatet gedacht werden, die sich in

51 HERMANN, Liebesdichtung, 76.

52 Dagegen führt die Bezeichnung der Gattin als Schwester in $12,10-20$; $20 \mathrm{zu}$ deren $\mathrm{Freisgabe.} \mathrm{Hier} \mathrm{liegt} \mathrm{ein,} \mathrm{wern} \mathrm{auch} \mathrm{betrügerisches} \mathrm{Verber-}$ gen des wahren Rechtsverhältnisses als Motiv der Travestie zugrunde.

53 Auf die Königstravestie scheinen auch die rätseihatten Kriegswagen des "Ammînadîb" Hl 6,12 zurückzugehen, dessen Name wohl das gleiche Semantem náḉ "edel, adilig" wie bat-nădîb 7,2 enthält.

54 Die Sammlung, nicht die einzelnen Stücke, deren uneinheitliche Herkunft im einzelnen schwer zu bestimen ist, gehört m.E. ins 3.Jh.v.Chr. (vgl. vf.: ZThK 73, 37f., ähnlich EISSFELDT, Einleitung 664, HENGEL, Judentum 201, KAISER, Einieitung 327, u.a.); damit wird eingeräumt, daß die Königstravestie in anderen leiten andere Funktionen hatte. Zur Beziehung Qôhäläts zum H1 und derr sozialgeschichtlichen Ort beider Texte vg1. Vf.: ZAW 90, 252-254. 
der ländlichen Hirtentravestie von H1 1,7f. - wie bei dem gleichzeitigen Theokrit und bei anderen Exponenten einer überfeinerten hellenistischen Kultur - geltend macht; dabei ist nicht auszuschlielen, daß das Hohelied Konventionen der hellenistischen Literatur auch dann übernimmt, wenn diese den sozialen Bedingungen ihrer Vorbilder besser entsprechen als den eigenen $^{55}$.

f) Weitreichender noch sind diejenigen geselligen Travestien, in denen dem Besungenen mit einer Art theomorpher Steigerung ${ }^{56}$ Götterrollen auferlegt $\mathrm{zu}$ werden scheinen 57 . Die Anreden sind dabei mit einem staunend-fragenden mi zót "wer (ist) es?" eingeleitet $(3,6 ; 6,10 ; 8,5)$, das die folgenden Inhalte in eine Schwebe des Unwirklichen, ja ironisch-Utbertrietenen bringt.

55 Zur 'Travestie nach unten' (Vogelfänger, Gärtner, Fellache u.ä.) in der altägypti.schen Liebeslyrik vg1. HERMANN, Liebesdichtung 119-124. Die hellenistische Hirtenpoesie nimmt dagegen mit den prosaischen Mimen des Sophron von Syrakus ihren Anfang und erreicht in der Bukolik des aus Syrakus gebürtigen Theokrit ihren Höhepunkt. - Wenn sich die hier übernommene Spätansetzung des $\mathrm{Hl}$ als Sammlung bewährt, muR allerdings die Nachtarschaft seiner Gedichte zu denen des alexandrinischen Dichterkreises mit Kallimachos, Apollonius und Theokrit (dazu GEBHARDT) ebenso stark berücksichtigt werden, wie die altägyptische bzw. altsemitische Tradition der erotischen Poesie: so ergibt sich für das Hl eine ähnliche Genese wie für Qôhälät der Motive altorientalischer Skepsis und ihres Hedonismus (dazu 0. LORETZ, Qohelet und der Alte Orient, 1964) soweit aufnahm, wie sie dem hellenistischen Zeitgeist entsprachen, an dem er unmittelbar teilhatte (dazu R. BRAUN, Kohelet und die frühhellenistische Popularphilosophie, 1973). Einfluß aus dem ptolemäischen Alexandria auf das $H 1$ erklärt auch dessen ägyptisches Ambiente, auf das GERLEMAN so nachdrücklich hingewiesen hat; zu palästinischen Gegenstücken des Hl in griechischer Sprache HENGEL, Judentum 152-161.201.

56 Die "theomorphe Steigerung des Menschen" ist nach H. BLUMENBERG (Wirklichkeitsbegriff und Wirklichkeitspotential des Mythos, in: M. FUHRMANN [ed.] Terror und Spiel. Probleme der Mythenrezeption 1971, 11-66, bes. 13) die andere Seite einer "imaginative(n) Ausschweifung anthropomorpher Aneignung der Welt", wodurch Lyrik, zumeist in einer Art augenblicklicher Erinnerung, mythische Motive und Erlebnisstrukturen nachbildet.

57 Gottheiter als Vergleichsspender begegnen auch in der Anm. 29 genannten ugaritischen Beschreibung der Göttin $\mathrm{Pbl}$ :

"Gib mir die Dame $\not ̛ ̣ j^{2}$, die wohlgeborene, deine Erstgeburt, deren Anmut wie die Anmut cAnats deren Schönheit wie die schönheit der JAstarte ist..." 
Die aus der wïste heraufziehende Braut 58 erscheint nämlich 3,6 "wie (in) Säulen von Rauch" (anders 8,5), was die spielerische Assoziation einer Theophanie kaum ausschließen 1 äßt. Ähnlich wird ihr majestätisches Herabblicken "wie die Morgenröte" 59 (6,10[4]) entfaltend als "aa jumrā "schreckenerregend" bezeichnet ${ }^{60}$, was den Vergleich mit den offenbar numinosen ${ }^{61}$ nidgālot nach sich zieht; nach der Erwähnung von Morgenrot, Mond und "Glut" (Sonne im unmittelbaren Zusammenhang muß bei dem Pl.fem. nidgālót an "die (weithin) sichttaren (Gestirne)" 62 gedacht werden, etwa in Erinnerung an eine Sternrosette ${ }^{63}$, wie sie vorderasiatische Göttinnen in ihrer Rolle als "Himmelskönigin" tragen ${ }^{64}$.

Hält somit das spielerische Ausschweifen der Phantasie für das Mädchen nicht für den Mann ${ }^{65}$ - archaische Götterrollen bereit, so kann es nicht verwundern, daß in 8,6 die Liebe seltst als Cazzā kammāwät "stark wie der

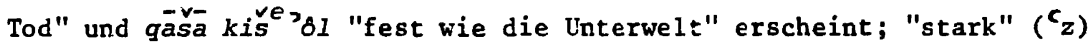

$58 \mathrm{mf}$ zót neutral zu fassen (WURTHWEIN, HAT I/18, 48f.) oder mah-zôt zu lesen (HALLER 32f.), besteht angesichts des eindeutig femininen Bezugs der Wendung in 6,$10 ; 8,5$ kein Anlaß.

59 Das $\mathrm{Hi}(+\mathrm{Ni}) \mathrm{S}_{Q P}$ ist nenominativ gegenüber šägäp*, der Bezeichnung für ein hochgelegenes (Ersqheinungs-) "Fenster" (K. CALLING - H. RöSEL, Biblisches Reallexikon ${ }^{20}$ ) am Tempel oder Palast.

60 Zur Rolle der (göttlichen oder königlichen) vom Fenster herabschauenden Frau vgl. für den syrophönizischen Raum FAUTH, Aphrodite parakyptisa, bes. 43-54.

6) Zum numinosen Charakter des als ${ }^{\supset} \overline{a j o ̄ m}$ nur noch Hab 1,7, sonst als $>$ êmā bezeichneten "Schrecken(s)" vg1. etwa H.J. ZOBEL: ThWAT I, 1973, 235-238.

62 Die Wurzel LGI hat, wie am deutlichsten akkad. dagālu(m) zeigt, die Bedeutung "schauen, blicken"; vgl. hebr. dägül "weithin sichtbar > hervorragend" H1 5,10.

63 Nach FAUTH trägt speziell die vorderasiatische Cöttin vom Typ der Parakyptusa auch Wesenszüge einer Himmelsherrin, zu deren Fmblemen Halbmond und Sonre (Aphrodite parakyptusa 72 ) Halbmond und Stern $(27.39)$ bzw. das ganze Sterrenfirmament (44f.) oder die Sternrosette (82.107) gehört. Zu Miinzdarstellungen des "Astartewagens" mit Sonne und Mond als Mitte1punkt des Tierkreises vgl. CESE, in: GESE - HÖFNER - RLDOLPH, Religionen 191 (Lit.).

64 Zur "Himmelskönigin" vgl. noch Jer 7,18; 44,17ff.; Hermopolis-Papyrus 4,1 .

65 Anders etwa Sappho 123 D., ein Hochzeitslied mit der Aufforderung, den Türsturz zu heben, damit der arȩsgleiche Bräutigam hindurchziehen kann, wofür M. TREU (Sappho. Lieder, 196?, 226) Ps 24 zum Vergleick heranzieht; er bemerkt dazu, "dies alte religiöse Motiv" könne "auf der Crenze von Ernst und Unernst mit komischen Übertreiburigen verbunden werden". 
ist zuvor schon Môt gewesen, die den Tod verkörpernde ugaritische Gottheit (CTA 6 [KTU 1.6] VI:17), woran überdies ein hebräischer Personenname wie "zmwt "stark ist Môt" 1 Chr 8,36 erinnert. Eine mythische Reminiszenz liegt auch vor, wenn die "Flamme" der Liebe in der Wendung $r^{e}$ šapâă rišpè 'ē̌̌ "ihre Flammer sind Feuerflammen" zunächst nach den mit vielfältigen Funktionen ausgestatteten Gott Rašap bezeichnet werden. Ob dagegen in salhäbätjä (?) das Element $-j \bar{a}$ wirklich die Kurzform des Gottesnamens darstellt, ist umstritten ${ }^{66}$; vielleicht hat es superlativische Funktion, etwa im Sinne von " $j$ ah(we)haft gewaltige Flamme ${ }^{67}$. Die Aura versunkener Gottheiten konnte als poetische Maske im lyrischen Spiel wiederkehren, sobald die Gefahr eines manifesten Abirrens zum Heidentum nicht mehr bestand vielleicht auch, weil in den Kreisen, die Dichtung von der Art des Hohenliedes pflegten, ohnehin kaum noch eine religöse Bindung verpflichtend war: so schien den Epigonen prophetischer und "aufgeklärter" Entmythisierungen nicht nur ein Experiment wie Pred 2,8;9,9, sondern auch eine flüchtig-subjektive Sakralisierung des Eros wieder tragbar. Möglich war diese, soweit die Gestalten der kanaanäischen Fruchtbarkeitsreligionen unbewußt noch lebendig waren. Die Aralyse der Texte muß dann gleichsam die religiöse Katrix erschließen, nach der deren Tiefenstruktur hinter einer profanen Oberfläche strukturiert ist. Die spielerische Sakralität des Eros var vielleicht für die Träger der Dichtung die einzig verbliebene Quelle numinoser Erfahrung überhaupt: in einer weithin desakralisierten Welt macht die lyrische Wirklichkeitsverwandlung etwas von der Heiligkeit des Lebens erfahrbar, wie denn überhaupt nur der unterbewußte vitalbereich der Beteiligten noch - im heidnischen Sinne - religiös gewesen sein mag.

\section{Die Vergleichserweiterungen}

Attributive oder adverbielle Vergleichserweiterungen haben gegenüber dem Vergleichskern vorwiegend a) lokalisierende oder b) beschreibende Funktion; beschreibende Erweiterungen können sich $c$ ) in tesonderen Nominalsätzen verselbständigen.

66 GERLEMAN, BK XVIII, 217, interpretiert $-j a \bar{a}$ nach H.S. WYBERG als Intensivsuffix.

67 Vgl. P.A.H. DE BOER, הiה as Epithet Expressing the Superlative: VT 24 (1974) 233-235. 
a) Mit der relativen Häufigkeit lokalisierender Vergleichserweiterungen ${ }^{68}$ ist die Dominanz der Raumes bzw. der Landschaft über das metaphorische Geschehen und die mit ihm befaßten Menschen angezeigt, was dem statischen Nominalstil seiner Schilderung entspricht; das Geschehen ist vergleichsweise zeitlos.

Oft spezifiziert die Lokalisierung des Vergleichsgegenstandes einfach dessen Bezeichnung. Der Selbstvergleich 2,1 präzisiert sich, indem er die "Narzisse" durch ein determiniertes Genitivattribut nach Saron, die "Lilie" in die "Ebenen" verweist. Der Vergleichsspender "Turm" 7,5b wird nicht nur durch den determinierten Genitiv hall eäanôn als "Libanonturm" spezifiziert; an das lokalisierende Attribut schliebt vielmehr noch eine Partizipia1konstruktion an: șopä pe nê dammāsśäq "der nach Damaskus blickt", worin die Lokalbestimmung adverbiell ist. In 7,5 stehen sogar zwei Präpositionalbestimmungen in Apposition zueinander: die Augen der Besungenen sind danach Teiche "in Hesbon, am Tor der volkreichen Stadt". - Dem modernen Geschmack mögen solche Erweiterungen als überflüssig erscheinen. Im Hohenlied dienen sie offenbar dazu, den Vergleichsspender genauer im sinnlich-Gegenständlichen zu befestigen. Konkrete Namen wie Saron, Damaskus und Hesbon oder Loka1bezeichnungen wie "Ebenen" und "volkreiche Stadt" mit der syntaktisch strengen, aber prosaisch wirkenden Determination der Genitivattribute 69 wie überhaupt die für poetische Texte ungewöhnliche Häufung der Determination im Hohenlied hindern den Vergleich daran, entsprechend seiner Funktion als eines bloßen Denkbildes aus dem Bereich des objektiv-Anschaulichen in den des Verschwommenen zu entgleiten ${ }^{70}$.

68 Nicht eigentlich hierher gehören also die gelegentlich in den Vergleich hineingeflochtenen Lokalisierungen des Vergleichsempfängers wie in "Deine Augen sind (wie die der) Tauben hinter deinem Schleier hervor" 4,1 (vg1. $4,3 b=6,7)$.

69 Auffällige Determinationen der_attributiven Genitive bei Vergleichen finden sich auch in ș rór hammōr bzw. "äškōl hakkōpär òôi lî (deutsch dagegen "ein Myrrhenbeutel" bzw. "eine fiennatraube ist mir mein Geliebter") 1,13f., ferner in ho bașsälät haššārón, šôšannat hāa māqîm $(2,1)$,

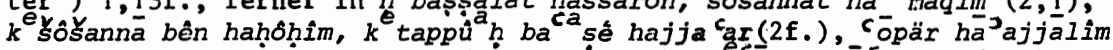
neben indeterminiertem 1 is sbi $(2,9,17 ; 8,14), k$ edär hácizzim $(4,1)$,

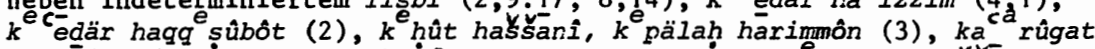
habbósäm (5,13, vg1. 6,2), 'aggan_hassahar $(7,3), k$ migdal hašsen, $k$ migdal hall banôn (5), ke äsk ${ }^{2}$ lot haggäpän neben determiniertem kattapụ̂́m (9), $k$ jên hațtób $(10, \operatorname{vg1} .8,2)$.

70 Eine ähnliche sinnlich-anschauliche Spezifikation des dichterischen Bildes vom Menschen im ganzen erreichen die Beschreibungslieder, indem sie die Einzelaussagen an den Körperteilen des Beschreibenen entlanggehen lassen: so wird selbst die Tänzerin von $\mathrm{Hl} 7,1-6$ gleichsam in die Summe ihrer Körperteile aufgelöst, obwohl der Vorgang des Tanzes die Bewegung jeden Augenblick ein Ganzes sein läßt. 
Gelegentlich kann eine Lokalisierung den Primärvergleich um ein neues tertium comparationis bereichern und dabei eine Konnotation explizieren: so wenn es von den $q^{e}$ subobt "Geschorenen" $(4,2)$ bzw. $r$ hẹelim "Mutterschafen" $(6,6)$ heiBt, daß sie "aus der Schwemme steigen"; das Analogon ist nun nicht mehr die große Zahl, sondern die Reinheit der verglichenen "Zähne" der Geliebten" 71 .

In anderen Fällen steigert die Lokalisierung den Wert des Vergleichsspenders; sie qualifiziert ihn gleichsam. Ob das schon bei der "Narzisse von Saron" $(2,1)$ mitklang, ist schwer zu entscheiden ${ }^{72}$. Ein wenig deutlicher scheint es zu sein, wenn die Hennatraube von 1,14 durch das Attribut $b^{e}$ karmó ${ }^{e} \hat{n}$ gä̈df auf den sprichwörtlich fruchtbaren Weinbergen der Oase Engedi beheimatet wird oder wenn es von der Ziegenherde in $4,1 \quad(=6,5)$ in einer Partizipialwendung heißt, daß sie vom Gebirge Gilead herabsteigt. Eindeutig ist es vollends, wenn die Geliebte 1,9 eine Stute "an Pharaos Wagen" genannt wird, die Lilie 2,2 "unter den Dornen", der Apfelbaum 2,3 unter wertlosen Wa1dbäumen hervorragt oder der "Gartenquell" bzw. "Brunnen lebenden Wassers" 4,15 als "der vom Libanon herabfliebt" beschrieben wird. Spezifisch poetischer Wert wird dem Vergleich mit Gazellen bzw. Zwillingen des Gazellenweibchens 4,5 schließlich durch die Partizipialwendung hāró ${ }^{c}$ Im baššošannIm "die in Lilien weiden" verliehen.

Mit der zuletzt genannten Vergleichserweiterung berühren sich diejenigen, die den Vergleichsspender mit atmosphärehaltigen Requisiten umgeben: so venn die Taube (n) "an Wasserbächen" (5,12a) oder "in den Felsenhöhlen, im Versteck der Felsensteige" $(2,14)$ gesucht wird; dabei soll weniger mit den nomina regentia ḩagwé "Höhlen" und sētär "Versteck" die Furchtsamkeit des Tieres assoziiert ${ }^{73}$, sondern vielmehr mit den determinierten nomina recta hassälac "der Fels" und hammadrēgā "die Felsterrasse" ein an den Landschaftsmerkmalen haftender Stimmungsrest ${ }^{74}$ mobilisiert werden. Ähnlich mag es bei

71 Schafe wurden vor der Schur in die Schwemme getrieben; so versychte man saubere Wolle zu erzielen (GALLING, Biblisches Reallexikon , 352).

72 Nach S. KRAUSS (MGWJ 78, 84) will sich die Braut in ihrer Ländlichkeit empfehlen; WURTHWEIN (HAT I/18, 43) denkt an die Fruchtbarkeit der Saronebene als Vergleichspunkt.

73 Sumerische Beispiele für die Lokalisierung der als Vergleichsspender gebrauchten Tauben in Mauerlöchern, in die sie sich ängstlich verstecken, bei HEIMPEL, Tierbilder 391-395.397/8.

74 Zum Terminus vgl. R. WEI.LEK - A. WARREN (Theorie der Literatur, 1972, 199), die sich dabei auf I.A. RICHARDS (Principles of Literary Criticism, 1924 ) berufen: danach hängt die Wirksamkeit eines Bildes von dessen Charakter als eines psychischen Ereignisses ab; das Bild sei ein "tberbleibsel" und eine "Stellvertretung" der Empfindung. 
Gaze1le und Junghirsch "auf den Balsambergen" $(8,14)^{75}$ bzw. "den Betherbergen" $(2,17 \mathrm{~b})$ sich verhalten. Lokalisierungen dieser Art, deren logische Klarheit - wie noch im Fall von "Myrrhenberg und Weihrauchü̈gel" $(4,6)$ unter dem Niveau des Begrifflichen bleibt, geben dem bezeichneten Geschehen einen genrehaften Hintergrund; umgekehrt bezeichnen Felsen, Felsterrasse und Balsamberge aber auch einen metaphorischen Raum, der von den Vergleichsempfängern allererst beseelt wird, so daß die Metapher nun auch umgekehrt zum Mittel einer anthropomorphen Naturaneignung wird.

b) Die beschreibenden Vergleichserweiterungen unterscheiden sich in ihren Funktionen von den entsprechenden Lokalbestimmungen nur wenig.

Wo sie sich wirklich auf den Vergleichsspender, nicht auf den Vergleichsempfänger beziehen ${ }^{76}$, können sie ebenfalls die gegenständliche Intensität des Bildes steigern, ohne doch die Zah1 der Vergleichsspender zu vermehren: so wenn das Balsambeet in 5,13a als Vergleichsspender für die Wangen durch die Partizipialwendung $m^{e}$ gaddälät ${ }^{77}$ märqāḥ̂m "das Würzkräuter trägt" spezifiziert wird, wo der Gewinn an sinnlicher Anschauung schon durch den Plural gegeben ist; ähnlich wird der Vergleich mit einem Garten bzw. Granatapfelhain in 4,12f. durch die Aufzählung von dessen Früchten V.14, unter anderen der uns schon aus 1,12 bekannten Narde, in sinnlich-gegenständlichen Details entfaltet ${ }^{78}$. Mit einer solchen Bildintensivierung kann in Erweiterung der Metapher auch eine Reminiszenz einhergehen, so wenn in 3,11 an den "König Salomo" als Substitutionsbegriff für den Geliebten die Wendung anschliebt: "mit der Krone, mit der seine Mutter ihn krönte am Tage seiner Hochzeit, am Tag seiner Herzensfreude".

75 Zum stimmungswert von härê $b^{e}$ sämîm ist vielleicht jüd.-aram. be sim/ bassìm "süß, lieblich, schmackhaft" zu vergleichen; J. LEVY, Chaldäisches Wörterbuch über die Targumim I, Nachdruck 1966, 102.

76 Gelegentlich sind auch Beschreibungen des Vergleichsempfängers in den Vergleich verflochten: so bezieht sich nôt pót mór Cóber "triefend von flüssiger Myrrhe" $(5,13)$ auf śiptôtāw "seine Lippen", nicht auf die masc. šóšannim "Lilien", mit denen die Lippen verglichen werden.

77 Punktation mit W. RUDOLPH, KAT XVII/1-3, 159.

78 Zur Verbindung "Garten" - "Früchte" vgl. das sum. Beispiel in Anm. 32, ferner Gudea Zyl B V 15 (Anm. 47). 
Attributive Adjektive wie "versenlossen" und "versiegelt" explizieren Konnotationen von substantivischen Vergleichen wie "Garten" bzw. "Quelle" $(4,12)$; ähnlich ist die Funktion des Parallelismus von "wie der Libanon" und "auserlesen wie Zedern" $(5,15 \mathrm{~b})$, wo die Vergleichsspender "Libanon/ Zedern" durch das Adjektiv "auserlesen" in ihrem Wert gehoben werden. Ebenfalls dienen attributive Partizipialwendungen der Höherwertung des Vergleichsspenders in Phrasen wie "(der Davidsturm)...schichtweise aufgebaut" $(4,4)$, "(Walzen aus Gold) besetzt mit Tarsissteinen" $(5,14 a)$, "(eine Elfenbeinplatte) bedeckt mit Saphiren" (14b) oder "(Alabastersäulen) gegründet auf Sockeln von Feingold" (15a).

Einen Empfindungsrest von bloß atmosphärischer Funktion schließlich scheinen die an jên hațtôb "köstlicher Wein"79 anschließenden Wendungen zu beschwören: "der mir leicht eingeht, an meinen Lippen und Zähnen 80 (hinab)gleitend" 81 " 7,10$)$, vor allem die Beschreibung des "Weizenhaufens" von $7,3 \mathrm{~b}$ als "von Lilien umhegt" 82 .

c) Vergleichserweiterungen in selbständigen Nominalsätzen können wieder Konnotationen des Vergleichs bewußt machen, so im Verhältnis von

"Wie ein Karmesinfaden (sind) deine Lippen"

zu

"und deine Rede (ist) lieblich" 4,3a)

oder von

"Wie ein Apfelbaum unter den Waldbäumen

so ist mein Geliebter unter den Jünglingen"

79 t6b wird schwerlich nach dem Arab. und Altsüdarab. als 'Wohlgeruch" zu verstehen sein, so daß jēn haţţôb als "Würzwein" wiederzugeben wäre (gegen WItRTHWEIN, HAT_I/18,64; Vg1. KBL 349/50 und HAL 356). Vielmehr ist ähnlich wie bei qanä hatțob Jer 6,20 , für das $q$ ne hațtôb zu lesen ist, und sämäm hațtôb 2 Kön 20,13 hațtốb nach Analogie adjèktivische Attribute zu fassen; zur Substantivierung von Adjektiven nach nomina regentia vg1. Syntax $\S 76 \mathrm{e}$. Für "Würzwein" steht überdies der Terminus jajin härägặ $(8,2)$ zur Verfügung.

80 Lesungen nach $F$. HORST BHS.

81 Die Wurzel $D B B$ ist Aramaismus für hebr. züB; vg1. HAL 200a.

82 Vg1. GERLEMAN, BK XVIII, 198: "Die zu reinen Ornamenten erstarrten Lilien haben ausschließlich stilistischen Zweck". 
$\mathbf{z u}$

"seine Frucht (ist) süß meinem Gaumen" $(2,3 a . b B)^{83}$.

Andere relativische oder selbständige Nominalsätze dienen dazu, den Vergleichsspender höher zu werten, etwa die Beschreibung der zahlreichen

"Herde Geschorener, die aus der Schwemme steigen",

"welche alle Zwillinge haben -

beraubt ist keines von ihnen" $(4,2 b[=6,6 b])^{84}$,

bzw. des "schichtweise gebauten Davidsturms":

"Tausend Schilde sind an ihm aufgehängt,

alles Rundschilde von Helden" $(4,4 \mathrm{~b})$.

Der Ürsprung solcher Figuren mag wieder in einer Art Sprachmagie liegen: die Bildsprache sucht ihre Kraft, die bezeichnete Sache zu verwandeln, offenbar voll auszuschöpfen oder gar zu steigern. Dabei wirken die längeren Erweiterungen wie Entfaltungen früherer Kurzformen; so konnte die Explikation klären, was schon immer implizit war. Spätestens hier jedenfalls läßt sich die Funktion des Vergleichs nicht mehr auf seine Zeichenfunktion für den Bildempfänger beschränken: das Bild als solches gewinnt durch Emanzipation der auf es gerichteten Einbildungskraft eine selbständige Gegenwart und Lebendigkeit ${ }^{85}$.

In der bezeichneten Weise kann sich die Einbildungskraft freiiich nur darum von einer konventioneller rezipierten Realität befreien, weil das kollektive Wahrheitsbewußtsein bereits einer Schwäche unterliegt. Solange die Gesellschaft die Realität in allgemein verbindliche Begriffe zu fügen vermag, ist auch die Einbildungskraft an diese gebunden. Verlieren die Begriffe aber an Kraft, so eröffnet sich für die Einbildungskraft ein Feld der Freiheit oder der Willkür.

83 Nicht ganz $\mathrm{klar}$ ist die Funktion der Vergleichserweiterung in 7,6, wo auf den Vergleich des herabhängenden Haupthaars mit Purpurwolle ein selbständiger Nominalsatz folgt: mäläk ’asûr băr hătim "ein König ist in ...?. gefangen". Um eine bloße Angabe des tertium comparationis zu dem unmittelbar vorangehenden Vergleich wie in den Beispielen S.27 kann es sich nicht handeln: das Motiv vom_gefangenen König schießt auf jeden Fall über. - Die thersetzung von $r$ hätîm mit "Locken, Ringeln" (zuletzt KRINETZKI, NEB, 23) beruht auf reiner Vermutung; vgl. GERLEMAN, BK XVIII, 194.199.

84. Eine wie große Rolle beim Vergleich mit dem Mutterschaf dessen Trennung bzw. Nichttrennung von seinem Lamm spielt, zeigen die Vergleiche bei HEIMPEL, Tierbilder $\mathrm{Nr}$.14.6-14.10.

85. Ein anschauliches griechisches Pendant ist die Schilderung des Mondes in Sapphos Gedicht für Arignota 98D. Z.8ff.. 
III. Dissonanz von Realität und Metapher

Der Gegensatz zwischen der Realität des beschriebenen Gegenstandes und dem Ergebnis seiner sprachmagischen Verwandlung durch den Vergleich bzw. die Metapher wird gelegentlich noch dadurch besonders fühlbar, daß sich der Vergleich bzw. die Metapher einer semantischen Dissonanz bedient: Vergleichsspender und Vergleichsempfänger enthalten in ihrem Verhältnis zueinander einen bezeichnenden Widerspruch. Der Vergleichsspender hat neben dem Vergleichsempfänger nicht bloß ein eigenes Gewicht; er verleiht diesem auch einen eigentümlichen, anders sonst nicht wahrnehmbaren Mehrwert. Hieraus erst ergibt sich ein Aufschluß über die kommunikative Funktion der Metapher, ihre pragmatische Leistungskraft.

\section{Metonymie}

Metonymischer Art sind solche Dissonanzen, in denen Vergleichserweiterungen anders als bei den eben besprochenen Amplifikationen zunächst nur im Blick auf den Vergleichsspender, nicht auch im Blick auf den Vergleichsempfänger sinnvoll scheiner.

a) Dabei kann die Nennung eines Vergleichsspenders die anderer Vergleichsspender nach sich ziehen, so daß das Eigenleben, das der Vergleich gewinnt, diesen vom Vergleichsempfänger allmählich entfernt.

Nahezu synonym ist noch das Verhältnis von Garten- und Quellvergleich in 4,12; die Konkurrenz, in der sich beide Vergleichsspender in ihrem Verhält-

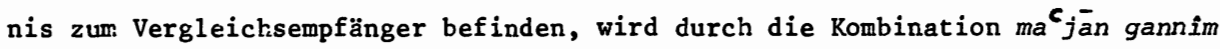
"Gartenquel1" $(4,15)$ eher künstlich ausgeglichen. In ähnlicher Weise synonym und darum konkurrentiel1 sind die Metaphern "Garten / Balsambeete" (6,2a; vg1. 4,16), "Myrrhenberg / Weihrauchhügel" (4,6), "Lilie / Myrrhe" $(5,13 b)$ und "Würzwein / Granatapfelsaft" $86(8,2)$.

Auf assoziative Weise zieht dann aber der Vergleich mit dem reichgeschmückten "Pferd" in 1,9 die "Streitwagen Pharaos" 87 oder der Vergleich mit dem

86 Das Suffix der 1.P.sing. in rimmônî enthält die Andeutung einer Verbindung von Vergleichsspender und Vergleichsempfänger.

87 Die so entstehende Montage von Tiervergleich und Königstravestie ist nur innerhalb einer imaginativen Kombinatorik auf der Bildebene sinnvoll; man braucht für die Verbindung von Stute und Streitwagen also nicht nach historischen Vorbildern zu suchen. 
"Weinberg" in 2,15 das Motiv "(kleine) Füchse" nach sich; man weiß aus der Konvention der Metaphern zwar, wofür "Weinberg" steht; wer aber im metaphorischen Sinne die Füchse sind, die den "Weinberg" verwüsten, wenn sie nicht gefangen werden, wird schalkhaft verborgen. Der Vergleich der Liebe mit "Wein" in 2,4 1äßt V.5 "Traubenkuchen" und "Äpfel" anschließen oder, etwas kühner, "Honigseim", "Honig" und "Milch" $(4,11 \mathrm{a})$. Der Vergleich des Mädchens mit einer "Mauer" in 8,9 erwächst aus dem der Brüste mit "Türmen", wie V. 10 zeigt; daß dann die "Mauer" das entwickelte, die "Tür" das noch kindliche Mädchen ist ${ }^{88}$, darf der Leser wieder erraten.

Wenn dagegen der "Garten" von 4,12 durch "Nordwind / Südwind" sein Ambiente empfängt, so ist dessen Bezug zum Vergleichsempfänger von poetischer Rätselhaftigkeit. Eine eigentliche Inkongruenz gegenüber dem Vergleichsempfänger vollends entsteht, wenn sich aus der Metapher "Nußgarten" in 6,11 Folgebegriffe wie "Knospen des Ta1s", "Weinstock" und "Granatäpfe1" ergeben oder wenn vom Begriff "Feld" der Hörer zu Anschauungen wie "Weinstock", "Weinblüte" und "Granatapfel" geführt wird $\left(7,12 f_{\text {. }}\right)$. Weiß man auch hier, dab der "Nußgarten" hzw. das "Feld" die Geliebte darstellt, so ist es nun schon gar nicht mehr sinnvoll zu fragen, wie die anderen Metaphern im einzelnen zu entschlüsseln seien; insofern bilden die Vergleichserweiterungen gegenüber den Bezeichnungen des Vergleichsempfängers wieder ein Oxymoron, das wegen der vielschichtigen Obertöne seiner Begriffe schon in der Antike von verschiedenen Hörern auf durchaus individuelle Weise gelöst und gedeutet worden sein mag.

b) Eine semantische Dissonanz enthält auch die adjektivische Prädikation "unser Bett ist grün ( $r a^{c a}$ nän)" in 1,16b. Zu dem nicht-metaphorischen Gegenstandsbegriff Caršenú "unser Bett" wird ein Prädikat gestellt, das nur auf ein metaphorisches Substitut dieser Gegenstandsbezeichnung wie etwa "Feld" oder "Baum" 89 paßt; der Ausdruck ist insofern elliptisch. Allein im Blick auf ein solches Substitut des Subjekts wäre auch der in der Exegese gelegent1ich assoziierte Gedanke an ein rituelles Beilager sinnvoll, das etwa auf dem Feld $(7,12 f$.$) oder unter einem Baum (8,5 b)$ begangen würde. - Die gleiche logische Struktur bestimmt in 2,16 und 6,3 das Verhältnis von Substantiv

$88 \mathrm{Vgl}$. WURTHWEIN, HAT I/18,69f.

89 GERLEMAN, BK XVIII, 114 , bemerkt zu recht, daß ra cänan fast immer von Bäumen gebraucht wird; nur dazu passen auch die folgenden Materialangaben für Hausbalken und Dachsparren, nämlich Zedern und Zypressen. Daher wählen wir die tbersetzung "grün" statt des sonst vorgeschlagenen Adjektivs "üppig" o.ä.. 
und partizipialem Attribut: "mein Liebster ..., der in Lilien weidet" (vgl. 4,5$)$.

c) Wird aus einem einzelnen Vergleichsmotiv ein Motivgefüge, so kann dies auch metonymische Tätigkeitsaussagen enthalten, die in erster Linie auf den Vergleichsspender, nicht so sehr auf den Vergleichsempfänger beziehbar sind. Der Vergleich der Braut mit einem Garten oder Weinberg etwa zieht eine Reihe von Verben der Bewegung nach sich, die in ihrer Spezifizität allein der Bildhälfte der betreffenden Rede angehören: so fiLx "gehen" $(4,6 ; 7,12)$, $B \bar{O}$ "kommen" $(4,16 ; 5,1 a)$, JS $S^{\supset}$ "hinausgehen" $(7,12)$, JRD "her-/hinabsteigen" $(6,2.11)$, aber auch $R^{\varsigma} h$ "weiden (lassen)" $\left(1,7 \mathrm{f} .{ }^{90} ; 2,16 ; 6,2 \mathrm{f}.\right)$ und $>_{R H}$ pflücken" $(5,1 \mathrm{a})$. Vor allem aber evozieren "Weinberg" und "Garten" mit ihren "Früchten" die Verbalmetaphern des Essens, Trinkens" und des SichBerauschens, die in 5, lb nur durch den Adverbialis câdim "an Liebe" mit der Realität verknüpft werden. Andere Verben der Bewegung wie Hi PüH "durchwehen" $(4,16), L Q T \underline{T}$ "pflücken" $(6,2), C_{L H}$ "besteigen" und ${ }_{H Z}$ "ergreifen" $(7,9)$ sind nur im Zusammenhang anderer Metaphern wie "Nordwind / Südwind", "Lilie", "Palme"92 oder "Rispen" sinnvoll. Ebenso ist das änigmatische Aufbauen ( $B N H$ ) einer silbernen Zinne bzw. das Verrammeln (? mit einer Zedernplanke außerhalb des Vergleichs mit Mauer und Tür 8,9 unverständlich. Nicht mehr deutlich ist der metaphorische Zusammenhang, in dem die Tätigkeitsaussagen $\boldsymbol{C}_{L H}$ min-hammidbär "aus der Wüste heraufkommen" $(3,6 ; 8,5)$, BŌ mill bānôn "vom Libanon kommen"93 $(4,8)$ oder šü mërôs sämänä "herabsteigen vom Gipfel des Amana" mit seinen anschließenden drei plerophorischen Lokalbestimmungen $(4,8)$ einmal ihren Platz hatten. Das gleiche gilt von der Beschreibung des "Geliebten" als "ïber die Berge springend, über die Hügel hüpfend" $(2,8)$.

90 Das transitive $R^{\prime} H$ "weiden lassen" $(1,7)$ leitet zur Hirtentravestie über, was auch durch das Parallelwort Hi RBS "lagern lassen" angezeigt wird.

$91 \mathrm{Zu}$ 'Essen' und 'Trinken' als Metaphern für Liebe und geschlechtlichen Ungang vgl. Ri 14,14; Spr 30,20 und vor allem El 4,16; 5,1; ferner C. LEVY-STRAUSS, Das wilde Denken, 1968, 126, M. ELIADE, Geschichte der religic̈sen Ideen 1, 1978, 23, u.v.a.

92 M. VON OPPENHEIM - D. OPITZ - A. MOORTCAT, Tell Halaf III: Die Bildwerke, 1955, Tafel 33a (dazu S. 52) gibt ein Kalksteinrelief aus dem 9.Jh.v.Chr. wieder, nach dessen Darstellung ein Mann auf einer Leiter zu einem Palmwipfel emporsteigt.

93 In 4,$16 ; 5,1$ enthält bereits $B \bar{O}$ "kommen" allein die Andeutung einer Verbindung von Vergleichsspender und Vergleichsempfänger und leitet so an den betr. Stellen zur Auflösung der Metaphorik über. 
d) Die in den zuletzt genannten Beispielen zu beobachtenden metonymischen Abwandlungen des Vergleichs unterscheiden sich von den vorher erörterten adverbiellen, attributiven oder selbständigen Vergleichserweiterungen dadurch, daß sie statt zu einer Bereicherung zu einem Zerfließen der Beziehung von Vergleichsspender und Vergleictsempfänger führen. Mit der begrifflichen Beziehung aber zerflieft auch die Anschaulichkeit. Die Akteure der betreffenden Cedichte bewegen sich gleichzeitig im metaphorischen Raum vie in der. der Realität. Iie Sprache trennt nicht zwischen dem Hinatsteigen in den Garten bzw. dem Weiden in Lilien und dem Garg zur Geliebten. Das eine wird curch das Gedicht als das andere erlebt.

Diese Beobach.tung scheint uns von grundsätzlicher Bedeutung zu sein. Einerseits ist das Zerfließen von Begriffsbeziehungen und Anschauurgen zwar schon von Anfang an in Vergleich und Metapher angelegt gewesen. Es gründet in deren Polysemie, im sprachmagischen tberhang, den Vergleich und Metapher gegenüber einem bloßen Bezeichnen der außersprachlichen Realität mit sich führen: die Realität gewinnt an Bedeutung. Vergleich und Metapher tragen uns aus der vorfindlichen Realität hinaus in ein Reich der Sprache, die ihren Wahrheitsanspruch lediglich aus der besonderen thberzeugungskraft dichterischer Suggestion bezieht. Fragen wir, worin die Bereicherung der Realität durch dichterische Sprache irhaltlich besteht, so zeigen die angeführten Beispiele, $c a ß$ die Ausweitungen des Vergleichs der Integration des Menschen in den Naturzusamnenhang dienen: Gärten und Wejinberge, das grüne Bett und die Bewegungen der Liebenden in der Natur repräsentieren eine verklärte Welt, deren der Mensch eir Teil zu werden wïnscht; Stimmungsreste des Naturerlebens halten gleichsam das Selbstgefühl der Sprechenden gefangen. Andererseits verschleiert das Ausufern der Vergleiche und Metaphern, die Redundanz an metaphorischen Zeichen aber auch einen offenbar unbewußt empfundenen. Mangel an Bedeutung der kloßen Realität, d.h. eine semantische Ohnmacht des Menschen ihr gegenüber: inder mit Hilfe metonymischer Vergleichsabwandlungen immer neue Zugangsmc̈glichkeiten zu der einen Wirklichkeit gesucht werden müssen, zeigt sich nämlich, daß die Wirklichkeit gerade in ihrer Einheit letz.tlich ohne zugang ist.

\section{Metaphorik im strengen Sinne}

Figen tlich metaphorischer Art sind semantische Dissonanzen zwischen Vergleichsspender und Vergleichsempfänger freilich erst da, vo die Substitution der Sache durch ein Bild beide nicht mehr durch ein stringentes 
tertium comparationis zu verbinden gestattet: hier kommt es nicht nur zu einem metonymischen Ausufern der Vergleichsbegriffe, wobei aus einem Assoziationsmechanismus heraus Figuren der Kontiguität gebildet werden; vielmehr stehen Vergleichsspender und Vergleichsempfänger nun vor vornherein in einem inkohärenten Verhältnis.

Oxymora in diesem strengen Sinne, wie sie etwa für die moderne Lyrik charakteristisch sind, finden sich im Hohenlied allerdings nur selten. Bei dem uns befremdenden Vergleich der Brüste mit "Gazellen / Zwillingen des Gazellenweibchens" $(4,5 ; 7,4)$ etwa haben wir noch nichts dergleichen vor uns; das natürliche Vergleichsglied ist hier nur im Ausdruck übergangen $^{94}$, wodurch sich die Analogie der verglichenen Größen dann freilich auch in der Anschauung verdünnt haben mag. Anders aber verhält es sich in der Travestie von 7,1-6, wo die gleiche Person auf der Realitätsebene eine $m$ hhôlat hamma ${ }^{2}{ }^{2}$ nájim "Tanz der beider Lager (?) / Tanz von Mahanajim (?)" vollführt, auf der metaphorischen Ebene aber den Hoheitsnamen Šulammît 95 führt, eine "Fürstentochter" ist und offenbar einen "König" gefangennimmt. So geschieht zwischen Realität und Metapher eine tberlagerung, die sich rational nicht mehr auflösen läßt. Die Benennung der lyrischen Akteure wird durch Begriffe der Königstravestie substituiert, die im Ausfall einer natïrlichen Analogie zum Benannten ihr Wesen hat. Die Metapher identifiziert das dinglich und logisch: Unvereinbare - um den Preis eines Verschwebens ihrer Aussage ins Irreale. Ist dann aber die Kontiguitätsstörung geradezu das Kunstmittel einer Metaphorik, die vom Widerspruch gegen die erfahrene Realität lebt, sollte die Exegese nicht länger ihren Scharfsinn auf die Herstellung einer sen:antischen Kohärenz richten, die die eigentümliche Poesie solcher Stücke geradezu zerstören würde.

94 Ein sum. Beispiel für eine solche Auslassung des tertium comparationis sind die 2.49f. des Hymus auf einer. Tempel in Kes:

"Das Haus, zum Himmel hin ein Wildschwein, zur Erde hin ein $d \grave{a} r a-m$ a š -Hirsch".

Was hier wie ein starkes Oxymoron wirkt, entpuppt sich in den nächsten zwei Zeilen aber nach einer Einführung des tertium comparationis als durchaus kohärenter Vergleich:

"Das Haus, zum Himmel hin wie ein Wildschwein braun,

zur Erde hin wie ein $d \grave{a} r a-m a \check{s}$-Hirsch lichtbraun". thersetzung nach HEIMPEL, Tierbilder 69ff.249ff.: vgl. J. KRECHER, Sumerische Literatur, in: Neues Handbuch der Literaturwissenschaft 1: Altorientalische Literaturen, 109 (Lit.), ferner DERS.: OLZ 73, 1978,145.

95 Die Erklärung von haššûlammft als Fem. von "Salomo" hat zuletzt vor allem RUDOLPH, KAT XVII/1-3, 170f., vertreten. 
So führen die Beobachtungen zu Metonymie und Metaphorik am Ende zu einem ähnlichen Ergebnis wie die syntaktischen und semantischen: Vergleich und Metapher lehen von einer Weise der Unverträglichkeit von intellectus und res, die keine Wahrheit gestattet, welche nicht in sich gespannt und widersprüchlich wäre. Wenn nun die Metapher auch für den Alten Orient als die dichterischste dex rhetorischen Figuren zu gelten hat ${ }^{96}$, so 1 iegt in der Erfahrung eines solchen Widerspruches, ja Wahrheitsentzuges die ontologischmetaphysische Voraussetzung für das Hervorbringen wie für das Verständnis von Dichtung überhaupt: deren Funktion ist es, den sonst sinnlosen Gegensatz von intellectus und res zwar nicht in einer gegenstandsorientierten adaequatio aufzulösen, wohl aber in einen kreativen zu verwandeln. Nur die Bildsprache ertägt diejenige semantische Dissonanz, ohne die Wahrheit offenbar gar nicht aussagbar ist. Eine Wahrheitsaussage, die eine semantische Dissonanz ertragen muß, ist aber umgekehrt immer zugleich auch Indikator eines Wahrheitsdefizits ${ }^{97}$. Eben ein solches Wahrheitsdefizit aber 1 äßt es insbesondere dem Zeitgenossen plausibel erscheinen, daß die Frage nach einer Wirklichkeit oder Wahrheit jenseits der Sprache als jhres jeweiligen Aneignungsmodus sinnlos ist, obwohl das erkenntnistheoretisch unreflektjerte Alltagsdenken diese Frage bejahend ertscheiden muß, wenn es sich nicht aufgeben will. Heute sind dichterische Metaphern nicht mekr nur Sprachornamente, auf die man allenfalls auch verzichten könnte; in dem Maße, wie ein gemeinsames sinnbewuksein schwindet, werden sie vielmehr zu so etwas wie dem Ersatz für eine natürliche Religion. So hat ihre Ästhetik zugleich etwas von implizierter Frömmigkeit.

96 Vg1. zur Formulierung KAYSER, Kunstwerk 112.

97 Zur Metapher als Indikator von Wahrheitsdefizit BLUMENBERG: ABG 6, 9. 
Die drohende Loslösung eines Reichs metaphorischer Sprache von der Realität kann freilich auch durch eine Art Gewaltstreich rückgängig gemacht werden, wenn die Figurationen des Vergleichs im lyrisch-dramatischen Spiel ritualisiert werden oder zu werden scheinen. Das sehr relative Recht der "dramatischen", aber auch der "kultischen" Deutung des Hohenliedes liegt darin, daß die Gedichte gelegentlich ein metaphorisches Verhalten der Liebenden darstellen, das gleichsam die Situation, aus der der Vergleich bzw. die Metapher erwuchs, noch einmal in einer veritablen Handlung aus sich heraussetzt.

Der Vergleich des Jünglings mit einem Apfelbaum $(2,3)$ scheint in $8,5 \mathrm{~b}$ die Vorstellung herbeizuführen, seine Mutter sei unter dem (sic!) Apfelbaum mit ihm in die Wehen gekommen ${ }^{98}$, wie denn auch jetzt seine Liebe unter dem Apfelbaum geweckt wird ${ }^{99}$. Die Exteriorisierung einer ähnlichen Metapher mag vorliegen, wenn nach 7,14 "Liebesäpfel" und allerlei "Köstlichkeiten" vor der Tür der Liebenden duften ${ }^{100}$ oder Myrrhenö1 sich nach 6,6 am Türriegel findet. Der realen Projektion von Bildvorstellungen mag dabei ein Wiedererwachen von Mythenmotiven zugrunde liegen, die ins Unterbewußte bzw. Unbewußte abgesunken sind ${ }^{101}$.

Ins Gegenständliche projiziert wird die metaphorische Substitution des Begriffs "Frau" durch "Garten" oder "Feld", wenn die Geliebte in Gärten wohnt $(8,13 a)$ oder wenn sie den Bräutigam auffordert, mit ihr aufs Feld zu gehen und bei den Hennasträuchern zu übernachten, um dann morgens in

98 Der Apfelbaum war auch der zyprischen Aphrodite heilig; vgl. FAUTH, Aphrodite parakyptusa 41 .

99 Das Motiv der Liebe unter Bäumen begegnet auch in der altägyptischen Liebeslyrik; vgl. HERMANN, Liebesdichtung 121. Für das Alte Testament ist an den Wortsinn von Hos 4,13 zu erinnern. Vgl. ferner KRAUSS, MGWJ 78, 93.

100 Die Andeutung einer Verbindung von exteriorisierter Metapher mit dem Vergleichsempfänger liegt in dem Satz "Mein Liebster, dir habe ich sie aufbewahrt" (14bB), der in die metaphorische Szenerie des Vorangehenden nicht ganz paßt; vg1. Anm. 15.

101 Noch nach dem Koran $(19,24)$ wurde Maria am Stamm einer Palme von den Wehen überrascht. 
die Weinberge zu wandern, wobei Weinstock und Granatapfel als Ambiente dienen (7,12f.; vg1. 8,5b). Man mag sich wie bei dem grünen Bett von 1,16 an archaische Sexualkulte im Freien erinnert fühlen ${ }^{102}$, ebenso wie manche Tiervergleiche an die heiligen Tiere bestimmter Gottheiten denken 1assen ${ }^{103}$. Durch eine dramatische Verifikation des Metaphorischen werden 1ängst versunkene mythisch-rituelle Muster belebt, wie es die analytische Psychologie auch yon Träumen, Imaginationen und schöpferischen Spontanleistungen des Individuums beobachtet.

Freilich verraten die Texte sonst nicht, wieviele der von Metaphern hergeleiteten Tätigkeitsaussagen wirkliche Vorgänge wiedergeben und welche sich etwa nur in einer "Welt der Dichtung" abspielen. Ersteres gilt wahrscheinlich von einem ritualisierten Heraufkommen aus der Wüste $(3,6 ; 8,5)$, insbesondere, wenn wir uns auch die mit dem beziehungsreichen Weiden(-Lassen) zusammenhängende Hirtentravestie $(1,7 \mathrm{f}$.) als naturreligiöse Zivilisationsflucht zu denken haben ${ }^{104}$, die eine Metapher in gegenständliche Realität transponiert ${ }^{105}$; für die veristische Umsetzung der königstravestie gibt es bekanntlich rezente Folklore-Parallelen ${ }^{106}$. Letzteres mag beim Kommen aus aus dem Libanon $\left(4,8^{107}\right)$, dem Springen bzw. Hüpfen über Berge und Hügel $(2,8)$ der Fall sein.

102 Zum Sexualverkehr ${ }_{3}$ im Freien vgl. Hos 4,13; 9,1; ferner die von WINANDY (Le Cantique $106^{23}$ ) gesammelten Theokrit-Stellen und die von KRAUSS (MGWJ 78, 93) aufgezählten rabbinischen Belege.

103 Hierher gehört die Taube (H1 1,15; 4,1; 5,12, vgl. die Anreden 2,14; $5,2 ; 6,9)$, die Gazelle $(2,9.17 ; 8,14)$ und das Gazellenkitz $(4,5 ; 7,4)$; vg1. Vf.: ZThK 73, 28/9.

104 In diesem Zusammenhang mögen die "Zelte von Qedar" $(1,5)$ so etwas wie ein ästhetisches Ideal abgegeben haben.

$105 \mathrm{Da}$ dabei eine Naturintegration ins Auge gefaßt wird, kann man auch darin angedeutet finden, daß das Weiden in den Lilien vom Menschen $(2,16 ; 6,3)$ wie von den Gazellen $(4,5)$ ausgesagt wird.

$106 \mathrm{Vg} 1$. J.G. WETZSTEIN, Die syrische Dreschtafel, Zeitschrift für Ethnologie 5 (1873) 270-302.

107 Auch GERLEMAN, BK XVIII, 152, findet hier "einen lyrischen Topos, ein verfestigtes literarisches Mittel, das Liebesleben konkret und spannungsvoll zu schildern"; das schließt eine mythische Reminiszenz freilich nicht aus. 
Gelegentlich ist das Oszillieren der Metaphern ins Wirkliche geradezu humoristisch, wie denn auch schon das theomorphe Ausstaffieren der Geliebten in 3,6; 6,4.10;-8,5 einen ironisch-übertreibenden Zug zu haben scheint. Das "Weinhaus" von 2,4 ist humoristischerweise zugleich symbolisch der Raum der Liebe ${ }^{108}$. Das Nebeneinander eine metaphorischen und eines dinglichen Gebrauchs der Metapher "Weinberg" gibt in 1,6 dem Mädchen die Möglichkeit zu einer leichtsinnigen Andeutung. Ähnliches gilt von der Beziehung zwischen Weinbergen und Füchsen in 2,15, wo die Realbedeutung noch viel stärker zurücktritt. 8,j]f. spielt dazu mit der Salomorolle in einer Königstravestie, um dann dem metaphorischen "Weinberg" der Liebe vor dem realen Weingut Salomos in Baal-Hamon den Vorzug zu geben: die realistische Verfremdung einer konventionellen Metapher und die dadurch erzielte semantische Dissonaz wird so zum Mittel, das eigene Meinen gängigen Wertungen selbstbewußt gegenüberzustellen; der Sänger tut beinahe nur noch so, als ob "sein Weinberg" mit den Weinbergen Salomos vergleichbar wäre, um dann davon überrascht zu sein, daß er es tatsächlich nicht ist. Ein ähnliches Sprachspiel geschieht in 6,8, wo die eigene Erwählte sechzig Königinnen und ihren Nebenfrauen vorgezogen wird, was wieder nur möglich ist, wenn die Figuren der Königstravestie in die Realität transponiert, d.h. gegenständlich genommen werden. Jedesmal zeigt sich die Kraft der Metaphern gerade in dem Maße, in dem sie in der Lage sind, den Hörer bzw. Leser durch ihre Transposition ins Reale dennoch von der Realität zu distanzieren: der tatsächliche Weinberg als sichere Einnahmequelle und die veritablen Königinnen bei Hofe können dadurch abgewertet werden; das sprachliche Verwirklichungsmittel ist ein humoristischer Zug, der einer semantischen Dissonanz abgewonnen wird.

Daß archaische Reminiszenzen, wie sie bei der Realisierung von Metaphern unterlaufen, in einem weithin säkularisierten Leben, wie es bereits hinter dem Hohenlied steht, nur noch der Vertiefung und Abwandlung lyrischer Stimmungen dienen, hatte die "kultische" Deutung des Hohenliedes übersehen. Der poetische Unernst der Reproduktion von mythischen Motiven schließt zwar nicht aus, daß diese immer noch von bestehenden Traditionen ihren Anstoß empfangen; aber die durch sie geleistete Daseinsaneignung ist augenblickhaft-individuell, ohne konstitutive Kraft für die Gesellschaft im ganzen.

108 Mit bêt hajjajin "Weinhaus" ist ebensowenig wie mit der Tafelrunde des Königs in 1,12 speziell an das Hochzeitshaus gedacht (gegen WÜRTHWEIN, HAT I/18, 42.44); vg1. Vf. : ZThK 73, $39^{4}$. 
So zeigt auch die Realisierung des Metaphorischen, daß die vorfindliche Wirklichkeit für den Menschen über ein Zuwenig an Bedeutung verfügt, weshalb sein alltägliches außerreligiöses Verhalten und dessen Semiotik ihr gegenüber versagt. Das Recht der in Handlung ungesetzten Metapher ist dann das gleiche wie das des metaphorischen Sprechens überhaupt: nur durch einen Gewaltstreich, der am Ende in eine humorvoll-ironische Distanzierung vom Vorgegebenen ausklingt, erlangt die Realität überhaupt noch einen sinnhaften Bedeutungszusammenhang. Metaphorische Sprache und metaphorisches Verhalten funktionieren - sprachmagisch - nach Art eines Analogiezaubers; insofern sich beide auf außersprachliche Realität beziehen, haben sie freilich auch etwas von einem Kontaktzauber. - Das Gelingen einer Metapher in Wort oder Handlung aber hängt in der Antike viel stärker als heutzutage von sanktionierenden Konventionen $a b$, die die metaphorischen Zuordnungen von Sachen und Bildern über lange Zeiten hinweg im Rahmen einer gesellschaftlichen Konstitution der sprachlich bewältigten Wirklichkeit verbindlich geregelt erhalten. Das macht die Differenz einer antiken Metaphorik gegenüber der geradezu privaten Metaphorik in der modernen Lyrik aus, obwohl gerade hier die Ohnmacht der Sprache gegenüber der Realität zumeist das Movens des Sprechens ist: man will konventionelle Metaphern bewußt aufheben, weil sie nichts mehr besagen; die Sehweise des Autors wird einsam und ist nur noch bedingt kommunizierbar.

Recht und Gelingen der sprachlichen Metapher reflektieren zuletzt die gleiche Unverträglichkeit von intellectus und res, wie sie auch dem religiösen Verhalten und Vorstellen zugrunde liegt. Im Gegenteil: im epigonalen Spiel des Hohenliedes scheinen sich eben jene Mythisierungen und Ritualisierungen strukturell zu wiederholen, die in der Frühzeit menschlicher Kulturentwicklung einmal die religiösen Bräuche und Bilder hervorgebracht haben, die sich danach zu agenda und credenda objektivierten. Freilich repräsentiert das Hohelied damit einen zweiten, nachkritischen Ernst im Gegensatz zu dem einer ersten, naiv-religiösen Wirklichkeitsaneignung; es ist der Ernst des Ästhetischen, in dem das Heilige nun gleichsam wiederkehrt. Wodurch sich nun aber die Verkleidung, die Degradierung des Heiligen in der ästhetischen Metapher von dessen ungebrochener, naiver Präsenz unterscheidet, ist eine eigentümliche Undeutlichkeit seines Ernstes: daß etwa die theomorphe Steigerung des Menschen gespielt wird, hat ein Wahrheitsdefizit zum Hintergrund; die Heiterkeit, ja der humoristisch-ironische Charakter dieses Spiels rückt es allenfalls in die Nähe echter Religiosität. 
Die theologischen Ergebnisse der vorangehenden Untersuchung, die über einen Beitrag zum Verständnis des Hohenliedes hinausreichen, sind nun zusammenzufassen. Sie betreffen das religiöse bzw. metaphysische Implikat, das mit dem Gebrauch von Vergleichen und Metaphern insbesondere dann gegeben ist, wenn diese inhaltlich aus älteren religiösen Vorstellungen und Verhaltensformen gespeist werden. Das dabei ins bloß Ästhetische abgesunkene Heilige scheint im Hohenlied zwar lediglich noch eine stilistische Funktion zu haben; insofern die stilistischen Figuren aber Äußerungen einer unbewußt religiösen Daseinsaneignung sind, läßt sich die in ihnen fixierte Erfahrung des Heiligen auch zu unmittelbarem Leben wiedererwecken. Ein solches Wiedererwecken versunkener, aber in der Sprache aufbewahrter Erfahrungen wird in einer sich immer schneller säkularisierenden Welt zur apologetischen Aufgabe des Exegeten und Theologen.

Freilich sind nicht alle ästhetischen Merkmale und Funktionen von Vergleich und Metapher zugleich auch von religiöser Relevanz; wir können uns darum an dieser Stelle auf die Weiterführung einiger linguistischer Grundbeobachtungen aus der vorangehenden Untersuchung beschränken.

\section{Zusammenf assung}

Zunächst erkannten wir die Funktion einer atavistischen Sprachmagie darin, daß sie den Vergleichsempfänger mit den Mehrwerten einer aus ferner Vergangenheit aufgespeicherten magischen Wirklichkeitsauffassung belebt, die ihm vom numinosen Charakter des Vergleichsspenders her zufließen. Der Vergleichsspender verwandelt, ja verzaubert dabei die von den Vergleichsempfängern konstituierte Welt in dem Maße, wie seine Wahl zunächst dissonant, ja befremdend wirkt.

Aus dem Bereich der Magie werden wir in den der mythischen Reminiszenz hinübergeleitet, wo lyrisch verklärte Menschen nicht mehr nur mit Sachen, Tieren und und Pflanzen oder mit Machtträgern wie der Erde verglichen werden, sondern eine theomorphe Steigerung finden, wo also Ausdrucksreste aus älteren religiösen Erfahrungen mit Göttergestalten auf sie übertragen werden. Dabei zieht der Mensch nicht nur einen Teil seines Ich zurück, um mittels des lyrischen Sprechaktes wieder zu einem Stück Natur zu werden; er wird zugleich auch in den Bereich und die Aura göttlicher Wesen versetzt, wenn auch nur $i$ in individuellen dichterischen Spiel des Augenblicks, das eine 
einst kollektive religiöse Geborgenheit in dürftigeren Zeiten ersetzen muß. Der Hintergrund einer solchen Pseudomorphose magischer bzw. mythischer Motive ins Ornamentale ist eine Schwächung nicht nur der gleichzeitigen Religiosität, sondern des kollektiven Wahrheitsbewußtseins überhaupt.

Entsprechend eröffnet die metonymische oder eigentlich metaphorische Dissonanz zwischen dem Vergleichsempfänger und dem Vergleichsspender sowie der in dieser Dissonanz verborgene Widerspruch zwischen Realwelt und metaphorischer Welt einen Raum poetischer Freiheit und Willkür. Zwar gewinnt die Realität dadurch für einen 1yrisch erhöhten Augenblick eine ihr sonst nicht zukommende Bedeutung. Aber dieser Bedeutungszuwachs ereignet sich nur noch in der Sprache, gleichsam in einem lyrischen $\mathrm{Als}-\mathrm{Ob}$ : die Literatursprache als nur-noch-künstlerisches Medium - verliert ihre Zeichenkraft für eine Realität, die dadurch einem zusätzlichen Bedeutungsverlust unterliegt. Die Sprache wird so zum Spiegel einer religiösen Desintegration, die im 3.Jh. v. Chr. die hellenistische Unterwanderung des Judentums, ja der Yerbindlichkeitsverfall von Tradition allgemein heraufführt; nicht zuerst ein bewußter Abfall zum "Götzendienst" als vielmehr das Schwinden religiöser orientierungen überhaupt war derzeit zu befürchten. So entstehen metaphorische Oxymora da, wo Vergleichsempfänger und Vergleichsspender nicht mehr durch ein stringentes tertium comparationis, sondern durch bloße Assoziation miteinander verbunden, oder besser: nicht verbunden sind, wo die Realwelt also normalerweise nicht mehr der Träger religiöser Bedeutungen, $j a$ von Bedeutungen überhaupt ist. Dafür wird die adaequatio inte1lectus et rei, seit scholastischen Tagen Inbegriff der Wahrheit, durch einen poetischen Gewaltakt des intellectus gegenüber der res verwirklicht: der intellectus kommt zur Wahrheit, nicht indem er der res entspricht, sondern indem er ihr widerspricht. Durch den Widerspruch der Metapher gegen die Realität ist sie Nachfolger, ja Ersatz einer natürlichen Religion.

Wird dabei vollends aus dem Gewaltakt der Poesie ein Gewaltstreich (imaginären oder wirklichen) poetischen Verhaltens, so mag man darin ein spätes, epigonales Analogon zu denjenigen Vorgängen sehen, die einmal zum Aufbau eines religiösen Wirklichkeitsverständnisses und religiöser Verhaltensformen überhaupt geführt haben - auch oder gerade wenn die analogen Vorgänge mit einem heiter-verspielten Unernst ablaufen, der sie von echter, ursprünglicher Religiosität unterscheidet. Es gehört zum Wesen einer religiösen Daseinsaneignung, daß sie die adaequatio intellectus et rei als assi- 
milative adaequatio rei ad intellectum wagt ${ }^{109}$, d.h. unter Transformation der res in eine Gestalt, die sie für den intellectus akzeptabel macht, in eine Gestalt also, wie sie nicht nur der Ordnungswille, sondern auch das Geborgenheitsbedürfnis des Menschen als menschgemäß und heimatlich erfährt. Religiöse Daseinsaneignung ist insofern eine subjektive Wirklichkeitsanverwandlung, zu der der Mensch im Maße seiner Andersartigkeit gegenüber der bloßen Dingwelt berechtigt ist und die ihm aus Vollmacht seiner Gottebenbildlichkeit gelingt. Die äußerlich-gegenständliche Wirklichkeitsadäquanz ist dann gerade kein Kriterium für religiöse Wahrheit, weder im Geschichtlichen noch im Dogmatischen;- die religiöse Wahrheit hat gegenüber der objektiven Beschreibung des Wirklichen vielmehr geradezu den Charakter einer Antierkenntnis, derer der Mensch zur Selbstbehauptung seiner Humanität gegenüber einer kalten Sachwelt, die ihn aufzusaugen droht, hochbedürftig ist. Solange die Begriffswelt die sich ihr aufdrängende Realität nur abbilden will, verliert sie die Andersartigkeit des Menschen gegenüber der Dingwelt, die humane Gottebenbildlichkeit, aus dem Auge. Im übrigen aber ist jede geistig-religiöse Assimilation der Wirklichkeit die Voraussetzung einer menschgemäßen Veränderung auch der Rea1welt, der allemal eine Weltyorstellung vorangeht, die ihre Berechtigung nicht in der Realität, sondern gegen sie sucht.

\section{Folgerungen}

Wir wollen diese Ergebnisse nun noch kurz in drei Richtungen weiterentfalten.

a) Wenn Vergleich und Metapher etwas von implizierter Frömmigkeit entfalten, so wird diese Frömmigkeit weithin von unterbewußten bzw. unbewußten Inhalten gespeist, von Vorstellungen und Verhaltensformen also, die bei sich verändernder oder schwindender Religiosität ins Unterbewußtsein bzw. Unbewußte abgedrängt wurden. - Dieser Vorgang beschränkt sich allerdings weder auf die Figuren Vergleich und Metapher noch auf das Hohelied. Wohl aber gibt es einen Hinweis darauf, daß alles deskriptive Reden von Gott metaphorische Implikate enthält und daß es die Inhalte solcher Metaphorik weithin aus dem Unterbewußtsein bzw. Unbewußten bezieht; die Metaphorik, die unser Reden von Gott in seinen Dienst nimmt, beruht weithin auf Inhalten, die unser Bewußtsein bestenfalls als überholt, schlimmstenfalls

109 Zu dieser Transformation der scholastischen Formel vgl. JÜNGEL in: P. RICOEUR - E. JÜNGEL $71 \mathrm{ff}$. 
als idolatrisch abwertet. Insofern stellt die spielerisch-nachreligiöse, individuumsbezogene Metaphorik des Hohenliedes gegenüber dem kollektiven Ernst einer ursprünglicheren Religiosität nicht einmal etwas grundsätzlich Neues dar. Schon Jesaja etwa konnte den Alleinanspruch Jahwes auf Israel, die Universalität von Jahwes Geltung und Herrschaft nur durchhalten, indem er auf Jahwe Vorstellungen und Funktionen kanaanäischer Götter, vor allem Els, übertrug ${ }^{110}$ : das Visionsbild von Jahwe als König in Jesajas Berufungserzählung (Kap. 6) verarbeitet eine pagane Motivik, deren Unterbewußtseinsfracht, träte sie bewußt zutage, die ganze Gewalt prophetischer Anklage auf sich zöge.

Geht nun eine Theorie der Interpretation mit J.G. HERDER, W. DILTHEY und der ihnen folgenden existentialen Hermeneutik von der Forderung eines "einfühlenden Verstehens" aus, so darf sich diese Einfühlung keineswegs auf bewußte Inhalte beschränken;- die "Kunst der Interpretation" im Sinne E. STAIGERS müßte vielmehr darin bestehen, entsprechend der psychischen Mehrdimensionalität auch des gegenwärtigen Hörens einen Text mit seinen Bewußtseins- und Unterbewußtseinsgehalten zu vergegenwärtigen. Eine solche Interpretation, die als Adressaten den gegenwärtigen Hörer in seiner Ganzheit vor Augen hat, geschieht unter der Voraussetzung, daß magische und mythische Strukturen potentiell auch noch in unserem BewuBtsein anwesend sind; sie durch Interpretation antiker Texte virulent werden zu lassen, wäre der Versuch, zu Unrecht Vergessenes, Verschüttetes und Verdrängtes heilsam zu integrieren ${ }^{11 \mathrm{~J}}$ und sich zugleich von einer perspektivelosen Fixierung auf das Gegenwärtige zu befreien ${ }^{112}$. - Der wissenschaftstheoretischen Problematik solcher Versuche muß man sich freilich bewußt bleiben.

110 Vgl. Vf., Die Funktion des Mythischen in der Prophetie Jesajas: Kairos i3 (1971) 266-281; Glauben und Bleiben. Zur Venkschrif Kap. 6, 1-8,18: SVT 26 (1974) 25-54.

111 Hier ist besonders auf die Aufwertung des Mythischen durch C.G. JUNG und von ihm beeinflußte Religionshistoriker wie M. ELIADE, K. KERENYI u.a. hinzuweisen; ELIADE wurde eingangs zitiert.

112 So hat es B. MALINOWSKI als die Aufgabe der Anthropologie bezeichnet, "unsere eigene Mentalität aus der entfernten Perspektive des Steinzeitmenschen" zu erforschen; ihr Ziel sei es, "auf diese Weise ein Gefühl für Proportion und ein feineres Gefühl für Humor (zu) geben" (Magie, Wissenschaft und Religion - Und andere Schriften, 1973, 127). Vgl. auch die schöne Veranschaulichung des Werts kulturgeschichtlicher Relikte in: "Ein kleines Glas Rum" bei C. LEVI-STRAUSS, Traurige Tropen (stw 240) $1978,377 f f$. 
Einerseits führt die Einfühlung ins Unterbewußtsein bzw. Unbewußte vergangener Texte in jedem Fall aus dem Bereich strenger Wissenschaft in den einer künstlerischen Divination; die Atmosphäre eines Textes geht ohnehin in keiner wissenschaftichen Beschreibung auf. Andererseits werden unterbewußte oder unbewußte Inhalte durch Interpretation vorwiegend vom Bewußtsein angeeignet und verlieren damit gerade den Zauber ïhrer Hintergründigkeit. Insofern bleibt jede Interpretation hinter dem Primärverstehen gleichsam tragisch zurück, wenn eben nicht auch sie künstlerisch mit dem nurAngedeuteten, Unausgesprochenen arbeitet, was aber der Orientierung von Interpretation am wissenschaftlich geklärten Begriff widerstrebt.

b) Ist von Gott notwendigerweise metaphorisch die Rede, und zwar unter In-Dienst-Nahme auch magischer und mythischer Vorstellungsinhalte, so geschieht dieses Reden gleichsam ís $\mu \dot{n}, \mathrm{~d} . \mathrm{h}$. mit demjenigen Vorbehalt, den Paulus 1Kor 7,29-31 für den Umgang mit den Gütern dieser Welt empfiehlt. Beruht vollends alle religiöse Wahrheit auf einer adaequatio rei ad intellectum, d.h, auf assimilativer Wirklichkeitsverwandlung, so greift eine "Entmythisierung" zu kurz, die sich nicht klar macht, daß sie an die Stelle des eliminierten Mythos jeweils einen neuen Mythos setzen muß; Gott kann nicht anders als in bestimmten welthaft-inadäquaten Gestalten, in Vorstellungen also, die allemal etwas Mythisches haben, in unserem Bewußtsein anwesend sein.

Sofern die in Dienst genommenen Vorstellungen also gegenüber der Größe und Güte Gottes niemals zureichen, gilt speziell von der religiösen Metaphernsprache, was THOMAS VON AQUIN়O beiläufig von aller Kreatur sagt: non est capax alicuius qualitatis infinitae ${ }^{113}$, und was in etwas anderer Form bekanntlich zu einem ontologischen Leitsatz reformierter Auseinandersetzung um das Abendmahl geworden ist. Das Herabkommen Gottes in dem Menschen Jesus hat an seinem Eingehen in mythische Gestalten der menschlichen Bewußtseinswelt allenfalls eine Analogie, weshalb keineswegs von der Inkarnation auf eine entsprechende "Realpräsenz" Gottes auch in religiösen Bewußtseinsbildern und ihrem sprachlichen Ausdruck zu schließen ist. Die mythische Gestalt, die Gott im Bewußtsein des Menschen annimmt, dient - anders als das Kommen Gottes in Christus - einem Erscheinen Gottes, das immer auch

113 Summa theologiae Suppl 99,1; den Hinweis auf THOMAS VON AQUINO verdanke ich meinem Kollegen O.H. PESCH (Hamburg). 
etwas ästhetisch-Anscheinhaftes hat, dessen sprachlicher Ausdruck also "nominalistisch" als bloß konventionelles Zeichen für die gemeinte Sache zu interpretieren ist.

Insofern die in Dienst genommenen Vorstellungen die Größe und Güte Gottes dennoch tatsächlich bezeugen, des Dienstes also an dieser Größe und Güte gewürdigt werden, gilt von ihnen mutatis mutandis der Satz der lutherischen Abendmahlslehre, quod finitum capax est infiniti, worin entsprechende positive Sentenzen der Scholastik, auch THOMAS VON AQUINOS ${ }^{114}$, aufgenommen werden. Durch das göttliche Sich-Hinabneigen in das Wort insbesondere erscheint dessen Metaphernsprache nicht nur als legitimiert; eine assimilative Wirklichkeitsverwandlung, die durch sie vermittelt wird, gelingt ihr dazu auch - und zwar im Sinne eines sprachphilosophischen "Realismus", der den Allgemeinbegriffen gegenüber der Wirklichkeit empirisch-gegenständlicher Einzeldinge eine sie relativierende Funktion einräumt.

Insofern die in Dienst genommenen Vorstellungen gegenüber der Größe und Güte Gottes nicht zureichen und sie dennoch zugleich bezeugen, ist dem Universalienstreit über die "Realität" des Ausgesagten in der Sprache, speziell aber dem Problem einer ontologischen Begründung der Logik des Metaphorischen seine Schärfe genommen. In jedem Fall ist im Gesagten vor allem das Sagen, im Gedachten das Denken zu schätzen, da allein in ihm die Dienstleistung yon Sprache und Denken liegt, während deren Inhalt immer der Gebrochenheit, des Unzureichens dieses Dienstes unterliegt. Das von uns vorgetragene Theorem trägt insofern trotz seiner christologischen Fundierung nicht dazu bei, einen grundsätzlichen Absolutheitsanspruch des biblischen Wortes gegenüber anderen religiösen Begriffssystemen zu begründen.

c) Das Hohelied, von dem unsere Untersuchung ausging, enthält keine explizit religiöse Botschaft. Diese hat sich gleichsam in eine Tiefenstruktur seiner Sprache zurückgezogen. Der (heidnisch-)religiöse Charakter dieser Tiefenstruktur, genauer: ihr unterbewußt-unbewußter metaphorischer Inhalt offenbart als solcher zwar keinen ontologischen Transzendenzbezug der menschlichen Existenz: die religiösen Sprachinhalte der im Hohenlied aufgefundenen Tiefenstruktur sind geschichtlich vermittelt und darum nicht unmittelbar metaphysisch bedingt. Aber auch so zeigen sie etwas von der fortwirkenden Kraft religiöser Daseinsaneignung, die über den Geltungsraum einer bewußten Frömmigkeit hinausreicht.

$114 \mathrm{Vgl}$. Indices zur Editio Leonina, s. 401. 
Das Heilige ist freilich ins spielerisch-ësthetische transponiert, was um so leichter geschehen konnte, als die Zeugniskraft des Schönen sich überhaupt in einiger Analogie zur Zeugniskraft der religiösen Metaphernsprache befindet. So wie die Metapher bei aller In-Dienst-Nahme nicht zureicht, die Größe und Güte Gottes zu umschreiben, so hat das "sinnliche Scheinen", das nach G.W.F. HEGEL das Wesen des Schönen bezeichnet, immer auch etwas Anscheinhaftes, d.h. den trügerischen Charakter des schọnen Scheins;- nicht von ungefähr wird der ästhetisch relevante Text, das Sprachkunstwerk, immer wieder der Verführung zum Eskapismus bezichtigt. So aber wie die Metapher doch des Dienstes an der Größe und Güte Gottes gewürdigt ist, so läßt der schöne Gegenstand - wiederum nach HEGEL - den eigenen idealen Begriff in seiner Existenz als realisiert erscheinen ${ }^{115}$. Natürlich beruht diese Entsprechung darauf, daß HEGELS Ästhetik in christlich-metaphysischen Entwürfen wurzelt. Aber das Schöne ist - als geschichtliche Erscheinung in unserem Lebensraum allemal Nachfolger des im christlichen Sinne Heiligen, das es ablöst, so wie die Ästhetik des Hohenliedes Nachfolgerin und Ersatz einer von ihr abgelösten altorientalischen Religiosität ist. Beidemal aber kann aus der Knechtsgestalt des bloß Metaphorischen, des Anscheins, mit dem man ästhetisch spie1t, die ursprüngliche Gestalt des Heiligen, in dem Gott erscheint, wiedergewonnen werden. In einer Zeit, da einerseits die ästhetische Wertung der Bibel weithin an die Stelle einer inspiratorischen getreten ist und Sakralkunstwerke aus den Kirchen in Museen und Konzertsäle auswandern und andererseits die profane Kunst sakrale Funktionen übernimmt und für viele dem Christentum Entfremdete zum Organ von Heilswahrheiten geworden ist ${ }^{116}$, wird das Bewußtsein des Heiligen durch die Begegnung mit dem Schönen zu neuem Leben erweckt werden können. Daß es sich

115 Vorlesungen über die Aesthetik, in: (ed.) H. GLOCKNER, Georg Wilhelm Friedrich Hegel. Sämtliche Werke 12, 1927, 160.164.

116 Ich erinnere nur an die "Artistenmetaphysik" GOTTFRIED BENNS und ihre Wirkungen in der Nachkriegszeit, an den Briefwechsel E. STAIGERS mit M. HEIDEGGER (STAIGER, Kunst 28-42), aber auch an die in Ost und West weitverzweigte Theoriediskussion über eine im sozialistischen Sinne politische Dichtung mit ihren Heilsmerkmalen. 
freilich mit dem Erscheinen der Wahrheit, das für den Christen mit dem Kommen Gottes identisch ist, denn doch noch etwas anders verhält als mit allen religösen Metaphern und deren ästhetischem Nachleben, mag am Ende ein Vers P. CELANS aus "Atemwende" (1967) ins Gedächtnis rufen:

Ein Dröhnen: es ist

die Wahrheit selbst

unter die Menschen

getreten

mitten ins

Metapherngestöber. 
Ausgewählte Literatur zur Thematik der Arbeit

BARRELET M.Th., Les déesses armées et ailées, Syr 32 (1955) 220-260.

DIES., Deux déesses syro-phéniciennes sur un bronze du Louvre, Syr 35 (1958) 27-44.

BLUMENBERG H., Paradigmen zu einer Metaphorologie: ABG 6 (1960) 7-142.

EISSFELDT 0., Einleitung in das Alte Testament, ${ }^{4} 1976$.

FALKENSTEIN A., Sumerische religiöse Texte 6: Ein sumerischer Liebeszauber: ZA 56 (1964) 113-129.

FAUTH W., Aphrodite parakyptusa, Untersuchungen zum Erscheinungsbild der vorderasiatischen Dea Prospiciens (Akademie der Wissenschaften und der Literatur. Abhandlungen der geistes- und sozialwissenschaftlichen Klasse, Jahrgang 1966, Nr. 6), 1967.

GEBHARDT C., Das Lied der Lieder, 1931.

GERLEMAN G., Ruth - Das Hohelied (BK XVIII), 1965, ${ }^{2} 1981$.

GESE H. - HÖFNER M. - RUDOLPH K., Die Religionen Altsyriens, Altarabiens und der Mandäer, 1970.

HALLER E. u.a., Die Fünf Megilloth (HAT I/18), 1940, 21-46.

HEIMPEL W., Tierbilder in der sumerischen Literatur, 1968.

HERMANN A., Altägyptische Liebesdichtung, 1959.

HERRMANN W., Gedanken zur Geschichte des altorientalischen Beschreibungsliedes: ZAW 75 (1963) 176-197.

DERS., Yarih und Nikkal und der Preis der Kutarät-Göttinnen. Ein kultisch-magischer Text aus Ras Schamra, 1968.

JÜLICHER E., Die Gleichnisreden Jesu 1/2, Nachdruck 1963.

JÜNGEL E., Metaphorische Wahrheit, in: P. RICOEUR - E. JÜNGEL, Metapher. Zur Hermeneutik religiöser Sprache, 1974, 71-122.

KAISER O., Einleitung in das Alte Testament, ${ }^{4} 1978$.

KAYSER W., Das sprachliche Kunstwerk, ${ }^{16} 1973$.

KRAUSS S., Die Landschaft im biblischen Hohenliede: MGWJ 78 (1934) 81-97.

KRINETZKI L. (=G.), Das Hohelied. Kommentar zu Gestalt und Kerygma eines alttestamentlichen Liebesliedes, 1964.

DERS., Hoheslied, in: W. DOMMERSHAUSEN - G. KRINET7KI, Esther - Hoheslied (NEB), 1980.

MÜLLER H.-P., Die lyrische Reproduktion des Mythischen im Hohenlied: ZThK 73 (1976) 23-41.

DERS., Poesie und Magie in Cant 4,12-5,1: ZDMG Suppl. III/1 (1977) 157-164. 
DERS., Neige der althebräischen "Weisheit". Zum Denken Qôhäläts: ZAW 90 (1978) 238-264.

von RAD G., Weisheit in Israel, ${ }^{2} 1982$.

RICOEUR P., Stellung und Funktion der Metapher in der biblischen Sprache, in: P. RICOEUR - E. JÜNGEL, Metapher. Zur Hermeneutik religiöser Sprache, 1974, 45-70.

RINGGREN H. - KAISER 0., Das Hohelied - Klagelieder - Das Buch Esther (ATD $16 / 2$ ), 1981 .

RUDOLPH W., Das Buch Ruth - Das Hohelied - Die Klagelieder (KAT XVII/1-3), 1962.

SCHMÖKEL H., Zur kultischen Deutung des Hohenliedes: ZAW 64 (1952) 148-155.

DERS., Heilige Hochzeit und Hoheslied, 1956.

SELLIN E., Lukas als Gleichniserzähler. Die Erzählung vom barmherzigen Samariter: ZNW 65 (1974) 166-189; 66 (1975) 19-60.

DERS., Allegorie und "Gleichnis": ZThK 75 (1978) 281-335.

STAIGER E., Grundbegriffe der Poetik (dtv.wr 4090), 1971.

DERS., Die Kunst der Interpretation. Studien zur deutschen Literaturgeschichte (dtv.wr 4078), 1971 .

WEDER H., Die Gleichnisse Jesu als Metaphern, 1980.

WEINRICH H., Sprache in Texten, 1976.

WESTERMANN, Das Schöne im Alten Testament, in: Beiträge zur alttestamentlichen Theologie.FS W. Zimmerli, 1977, 479-497.

WIDENGREN G., Hieros gamos och underjordsvistelse, Religion och Bibel. Nathan-Söderblomsällskapets Arsbok 7 (1948) 17-46.

WINANDY J., Le Cantique des Cantiques, 1960.

WITTEKINDT W., Das Hohelied und seine Beziehungen zum Istarkult, 1927. WÜRTHWEIN E. u.a., Die Fünf Megilloth (HAT I/18), ${ }^{2} 1969,25-71$. 
Bibliographische Abkürzungen

ABG Archiv für Begriffsgeschichte

Afo Archiv für Orientforschung

Amarna KNUDTZON, Die El-Amarna-Tafeln, 1 Bd., 1915

ANEP PRITCHARD (ed.), The Ancient Near East in Pictures Relating to the 01d Testament, 1954

ATD Das Alte Testament deutsch

BHS Biblia Hebraica Stuttgartensia

BK Biblischer Kommentar

CTA HERDNER, Corpus des tablettes en cunéiformes alphabétiques découvertes à Ras Shamra - Ugarit de 1929 à 1939, 1963

D. DIEHL, Anthologia Lyrica Graeca, 2 Bd., 21936-1942

dtv.wr Deutscher Taschenbuch-Verlag. Wissenschaftliche Reihe

HAL BAUMGARTNER u.a., Hebräisches und aramäisches Lexikon zum Alten Testament 1, 1967; 2, 1974

HAT Handbuch zum Alten Testament

Kairos Kairos. Zeitschrift für Religionswissenschaft und Theologie

KAT Kommentar zum Alten Testament

KBL KöHLER/BAUMGARTNER, Lexicon in Veteris Testamenti libros, 1958

KTU DIETRICH/LORETZ/SANMARTÍN, Die keilalphabetischen Texte aus Ugarit, 1: Transkription, 1976

MGWJ Monatsschrift für Geschichte und Wissenschaft des Judentums

NEB Die Neue Echter Bibel

OLZ Orientalistische Literaturzeitung

RLA Reallexikon der Assyriologie

stw Suhrkamp-Taschenbuch. Wissenschaft

SVT Vetus Testamentum. Supplementum

Syntax BROCKELMANN, Hebräische Syntax, 1956

Syr Syria

ThWAT BOTTERWECK/RINGGREN (ed.), Theologisches Wörterbuch zum Alten Testament, $1973 \mathrm{ff}$.

VT Vetus Testamentum

ZA Zeitschrift für Assyriologie

ZAW Zeitschrift für die alttestamentliche Wissenschaft

ZDMG Zeitschrift der Deutschen Morgenländischen Gesellschaft

ZNW Zeitschrift für die neutestamentliche Wissenschaft

ZThK Zeitschrift für Theologie und Kirche 